\title{
Development of Advanced Surface Enhancement Technology for Decreasing Wear and Corrosion of Equipment Used for Mineral Processing
}

\section{ANNUAL TECHNICAL PROGRESS REPORT}

(July 21st, 2004 - July 21st, 2005)

\author{
Dr. Daniel Tao \\ Department of Mining Engineering, University of Kentucky \\ 234E, MMRB, Lexington, KY 40506-0107 \\ Dr. Craig A. Blue \\ Oak Ridge National Laboratory \\ P.O. Box 2008 MS6083 \\ Oak Ridge, TN 37831-6083 \\ DE-FC26-03NT41787
}

August, 2005

University of Kentucky Research Foundation

201 Kinkead Hall, Lexington, KY 40506-0057

Oak Ridge National Laboratory

P.O. Box 2008 MS6083, Oak Ridge, TN 37831-6083 


\section{DISCLAIMER}

This report was prepared as an account of work sponsored by an agency of the United States Government. Neither the United States Government nor any agency thereof, nor any of their employees, makes any warranty, express or implied, or assumes any legal liability or responsibility for the accuracy, completeness, or usefulness of any information, apparatus, product, or process disclosed, or represents that its use would not infringe privately owned rights. Reference herein to any specific commercial product, process, or service by trade name, trademark, manufacturer, or otherwise does not necessarily constitute or imply its endorsement, recommendation, or favoring by the United States Government or any agency thereof. The views and opinions of authors expressed herein do not necessarily state or reflect those of the United States Government or any agency thereof. 


\begin{abstract}
Equipment wear is a major concern in the mineral processing industry, which dramatically increases the maintenance cost and adversely affects plant operation efficiency. In this research, a novel surface treatment technology, laser surface engineering (LSE) surface coating process was proposed for the surface enhancement of selected mineral processing equipment. Microstructural and mechanical properties of the coated specimen were characterized. Laboratory-simulated wear tests were conducted to evaluate the tribological performance of the coated components. Test results indicate that the wear resistance of ASTM A36 (raw coal screen section) and AISI 4140 steels can be increased 10 and 25 folds, respectively by the application of LSE process. Initial field testing showed a 2 times improvement of the service life of a raw coal screen panel.
\end{abstract}




\section{TABLE OF CONTENTS}

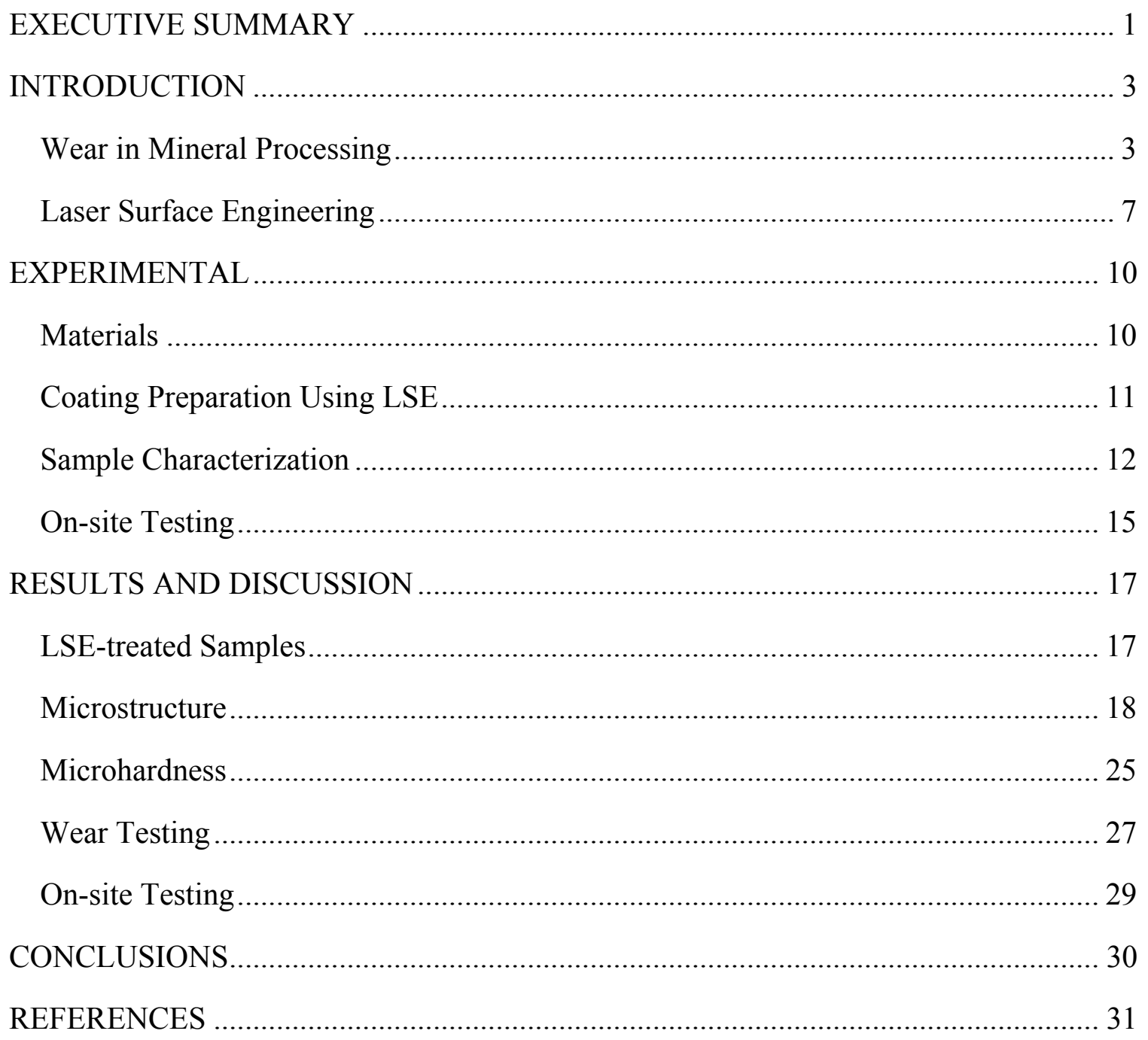




\section{EXECUTIVE SUMMARY}

This project is aimed at developing advanced surface enhancement technology for decreasing the wear and corrosion rate of mineral processing equipment by an order of magnitude. The proposed process is expected to be easily adaptable to automation and less expensive than currently used methods. Such performance improvement will result in energy savings of $2.45 \times 10^{14} \mathrm{Btu} /$ year. Significant efforts have been directed toward reducing wear of cyclones, pumps, heavy medium vessels, etc. used in mineral processing during the last two decades or so. Major progress has been achieved through the use of ceramic linings that have considerably increased the lifetime of hydrocyclones. However, little has been done to reduce the wear of screens, chains for conveyors, and piping where ceramic lining is impractical. The screen aperture increases as material wears, resulting in inconsistent aperture sizes and lower screening efficiency. This creates non-ideal feed to downstream operations, reducing their efficiencies. The wear of pipes, particularly the joint elbows, is another major concern of plant operators. The combination of corrosion and wear severely impacts the life span of chains, especially pin, bushings, and side plates. For horizontal conveyor systems, current materials used for chains include chrome-plated pins in an effort to minimize the combined wear/corrosion issues. However, stress-corrosion issues of chain components are continual problems. For inclined systems, corrosion issues are more limited; however, significant wear issues remain. Frequent replacements of screens, conveyors, and pipes increase equipment downtime and maintenance cost and reduce process efficiency. The development of advanced surface enhancement technology is of great interest for the mineral processing and coal preparation industry.

Laser surface engineering (LSE) coating technology has been successfully applied to surface enhancement of mineral processing components. Two substrate materials of AISI 4140 steel and ASTM A36 screen sections were coated by using LSE process. Coating materials such as $\mathrm{TiC}$ and $\mathrm{TiB}_{2}$ were investigated. The as-processed specimens were prepared for a series of characterization studies, including optical microscopy, scanning electron microscopy as well as X-ray diffraction for the microstructural examination, microhardness testing for hardness characterization, and finally the blockon-disk wear tests to measure the wear performance of the LSE processed coatings. A coated screen panel was installed at the coal processing plant for in-service evaluation. The following conclusions can be drawn from the results obtained from the study during the past year:

1. LSE technique has been confirmed as an effective means of producing wear resistant surfaces to meet the application requirements.

2. Surface coatings with refined microstructural features were obtained by using LSE coating process. Metallurgical bonds were formed between the coating and the substrate with the help of LSE process, which, in turn, increases the coating adhesive strength to the substrates.

3. EDS analysis provides the element distribution in the coatings. Higher amount of Ti was found near the coating surface whilst increased Fe was detected 
along the coating depth due to the convention effect of the LSE process.

4. XRD analysis confirmed the formation of new phases in the coating layer during the LSE process. This is characteristic feature of non-equilibrium synthesis by LSE process.

5. Of the four coated AISI 4140 specimens, Sample C3 ((Ni-10P)-50TiB $1250 \mathrm{~W}, 1500 \mathrm{~mm} / \mathrm{min}$ ) presented the highest wear resistance which is around 26 times higher that of the untreated AISI 4140 steel.

6. Sample S1 ((Ni-10P)-50TiC, $1500 \mathrm{~W}, 1500 \mathrm{~mm} / \mathrm{min})$ and $\mathrm{S} 3((\mathrm{Ni}-10 \mathrm{P})-$ $\left.50 \mathrm{TiB}_{2}, 1250 \mathrm{~W}, 1500 \mathrm{~mm} / \mathrm{min}\right)$ showed similar wear resistance enhancement during the wear test. The wear life of raw coal screen (ASTM A36 steel) increased about 10 times by applying these two coatings.

7. Initial on-site test using a coated screen panel with Metco 12C coating exhibited a 2-fold improvement of screen panel wear life. 


\section{INTRODUCTION}

\section{Wear in Mineral Processing}

Mineral processing is the science of separating valuable minerals from the gangue minerals out of ores to produce basic materials such as coal, quartz, salt, copper and gold that are used in the industry and everyday life. Mineral processing usually includes several unit operations, including comminution, classification/screening, concentration/processing and post-treatment (e.g., product dewatering). The mineral processing industry deals with a very large tonnage of mineral ores and products. Equipment wear happens inevitably in every stage of the process, which increases the equipment maintenance costs and plant downtime and reduces the process efficiency of the plant. Wear is believed to be one of the most significant problems in the mineral processing industry. It is estimated that up to $40 \%$ operating costs of a mineral processing plant are caused by equipment maintenance (Laurila and Budge, 2000). The equipment wear problems that exist in each of the aforementioned processes are discussed as follows:

Comminution is referred to as the gradual reduction of a hard mineral to a fine powder by crushing or grinding for direct use or further processing. This includes liberation of a product, such as coal from non-coal material. It also includes primary crushing, where run-of-mine ore is reduced to a size small enough to feed a secondary crusher and rock is broken down to an adequate size for grinding. Mineral comminution, especially grinding, requires large energy costs and may account for more than half of hard rock processing energy costs (Wills, 1985). According to the mining annual review conducted by the Mining Journal (1999), approximately 29 billion kWh of electrical energy is consumed each year for size reduction. Therefore, wear issues associated with this energy intensive process of comminution have been extensively studied and many approaches, from optimizing the equipment design to the development of wear resistant materials, have been adopted during the past two decades (Durman, 1988; Norman, 1980). The wear issues regarding comminution equipment is beyond the scope of this research.

Screening is a critical unit process in mineral processing. Screen (e.g., Figure 1) is the most commonly used device in the mineral processing industry to separate particles by size. Modern mineral processing would not be possible without efficient screening. In a coal processing plant, screening accomplishes sizing by passing coal of different sizes through a series of screens, each of a decreasing size. The individual screen discharges are then directed into different screen products for subsequent processing or sale. In processing industry, screens are also used for product dewatering, heavy media recovering, etc. (Leonard and Hardinge, 1991). During screening process, the aperture increases as material wears, resulting in inconsistent aperture sizes and lower screening efficiency because more oversize particles may report to the underflow, which as a result creates non-ideal feed to the downstream processes. 


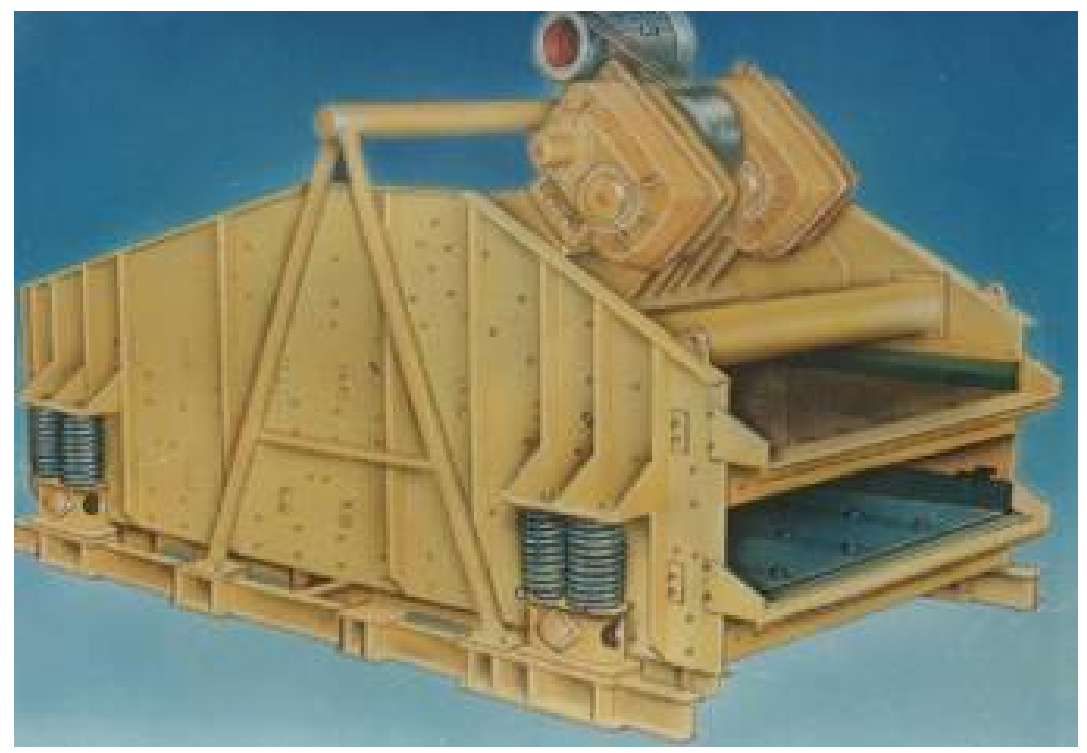

Figure 1. A typical vibrating screen for raw coal screening

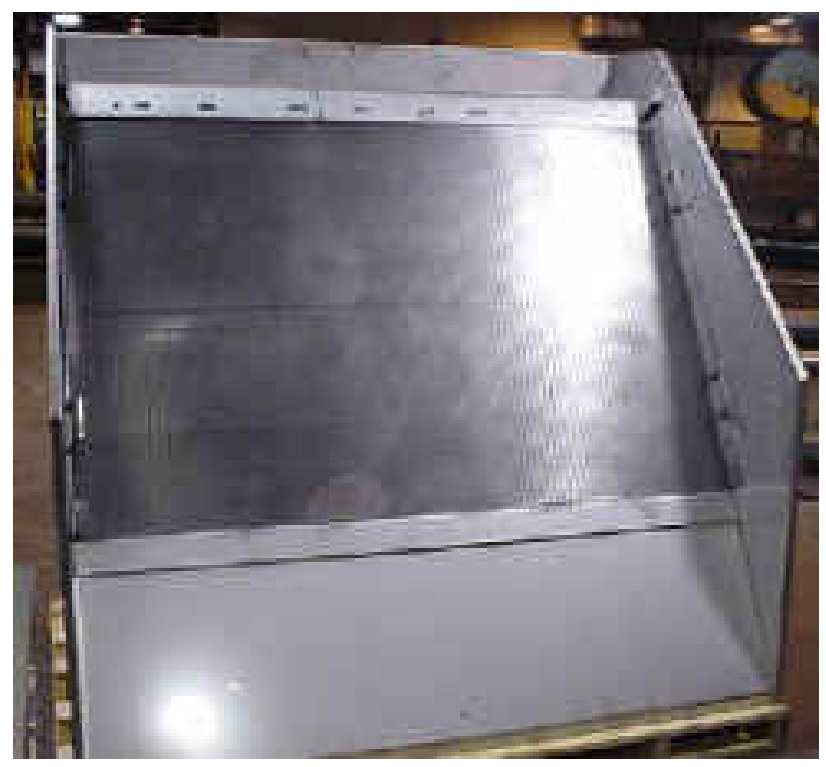

Figure 2. Sieve bend

Sieve bend (Figure 2) is another high capacity screening device widely used for fine particle $(150 \mu \mathrm{m} \sim 3 \mathrm{~mm})$ classification. Coal slurry is fed tangentially to the concave surface of a sieve bend, which provides a centrifugal force that presses the feed liquid layer against the screen surface. A shaving of liquid is formed due to the centrifugal force together with a retardation of the fluid velocity next to the screen (caused by frictional drag). Therefore, the particle classification is achieved when the shaved liquid enters the open slots and reports to the underflow stream. During fine 
particle classification, the bar between two adjacent slots of a sieve bend becomes rounded due to wear. Most sieve bends are made of stainless steels, and the wear life of most surface screens is usually between 1,000 and 2,000 hours of operation. Frequent replacement results in high maintenance costs.

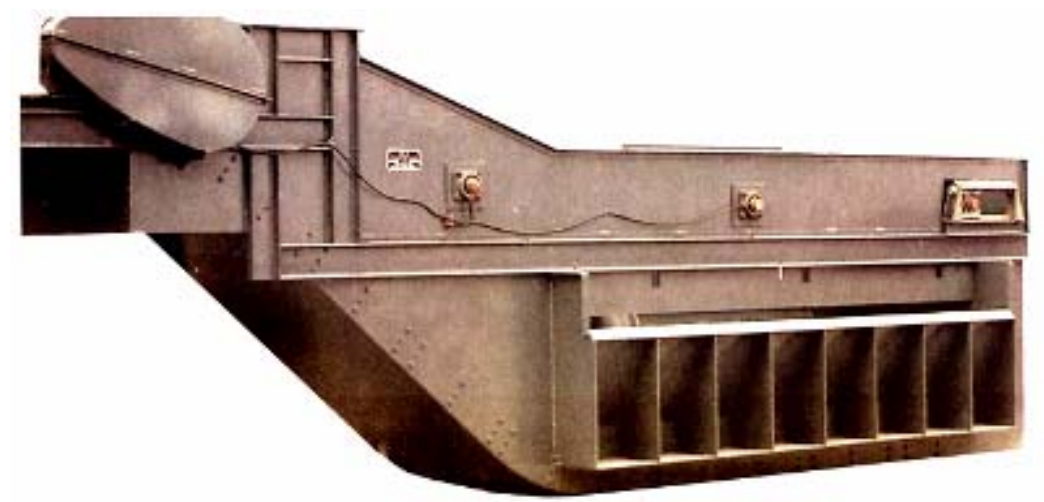

Figure 3. A typical dense medium vessel

Concentrating is the process of separating valuable minerals from their ores using the physical or physico-chemical property differences of different components. There are many mineral concentrating processes used in the coal and mineral processing industry. Dense medium separation process is the most widely used coal processing method, which accounts for $49 \%$ of the processing units used worldwide (Laurila, 1998). There are two types of dense medium separators in mineral processing, which are dense medium cyclone and dense medium vessel, as shown in Figure 3. Since ceramic linings have been developed and commercially used in dense medium cyclones to protect their inner walls (Foster, 1996), the wear enhancement of dense medium cyclones will not be covered in this research. It should be noted that the wear issues concerning heavy medium vessels which accounts for $26.3 \%$ of the coal preparation units in the United States (Laurila, 1998) have not been well addressed. In a heavy medium vessel, a feed sink plate is usually used to direct the feed (raw coal and dense medium suspension) downward into the vessel so that particles do not raft across the width of the bath. Thus, the plate is subject to high wear as the feed slides down along the plate into the vessel. 


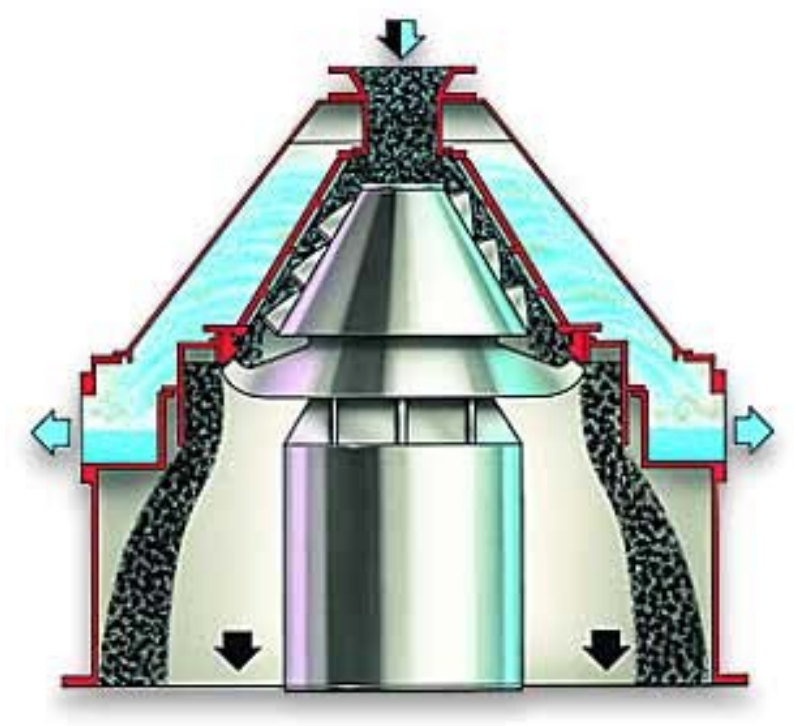

Figure 4. Schematic of a dewatering centrifuge

The purpose of product dewatering is to control the post-processed product, e.g., clean coal, to an acceptable moisture level. Centrifuge is commonly used in the coal preparation and mineral processing industry for product dewatering. A typical perforatebasket centrifuge is schematically shown in Figure 4. Centrifuges achieve separation by means of the accelerated gravitational force achieved by a rapid rotation. The separation is similar in principle to that achieved in a gravity separation process. The driving force is higher because it is resulting from the rotation of the liquid, unlike gravity sedimentation, where the driving force is from the difference in density between the solid particles and the liquid. The centrifuge separation is achieved with a force 1000 to 20000 times of the gravity. The centrifuge screen is subjected to wear when particles are pressed against the screen surface due to the high centrifugal force generated by the fast rotation.

It should be mentioned that the literature survey conducted by the author indicated that the equipment wear issue in mineral processing has not been well addressed. In the past, research efforts have been mostly focused on the wear problems of the energyintensive comminution equipment. Little work has been done on the study of wear enhancement of screening, heavy medium vessel and dewatering equipment. Although the energy consumption of these devices is much lower than that of the comminution equipment, wear deteriorates the separation performances of these devices and, as a result, affects the overall plant process efficiency is affected.

During the last two decades, significant efforts have been made to reduce wear of cyclones, heavy medium vessel, pipe lines and pumps which are widely used in mineral processing. The goal has been realized by using the ceramic linings to coat the inner surface of the high wear equipment (Foster, 1996). The different shapes of ceramic linings are installed inside the vessels and cyclones, which are much harder and have 
stronger wear resistance. They can greatly increase the lifetime of mineral processing equipment (Nonnen et al., 1985).

However, research has not been effectively performed to reduce the wear of screens, chains for conveyors and pug mill paddles for coal mixing, which have to be replaced very often as a result of wear. Due to size and complex geometry of screen, it is not feasible to apply ceramic lining to the screen. As the screen wears, the screen openings will become wider and wider. During this process, the screen loses the consistency of aperture and reduces the screening efficiency. The increased screen openings also reduce the efficiency of downstream operations due to non-ideal feed to them. Furthermore, the replacement of screens will increase the plant shutdown time and reduce the overall plant efficiency. The development of advanced surface enhancement technology and its application to screens and other equipment to enhance their wear lives are strongly desired by the mining and mineral processing industry.

\section{Laser Surface Engineering}

Steels are the most common materials of construction for the equipment used in coal/minerals mining and processing industry. Several reasons for using steels include: being the lowest cost material, readily manufacturable into complex shapes, and heattreatable by several techniques to obtain a range of surface and bulk properties. Surface coating as a manner of equipment wear life enhancement has been well established in engineering applications and many coating techniques have been extensively studied (Dowson and Taylor, 1985). Today, coatings are widely used for many purposes including the surface enhancement of different steels. Among the many surface treatment processes that are available today, lasers provide a unique tool for high quality surface modification. Many surface-related failures by mechanism involving wear, corrosion, erosion or high temperature oxidation can be minimized by laser surface modification (Mazumder, 1996; Steen, 1995). Surface modification using laser can take place in a variety of forms, depending on laser type and the materials to be treated.

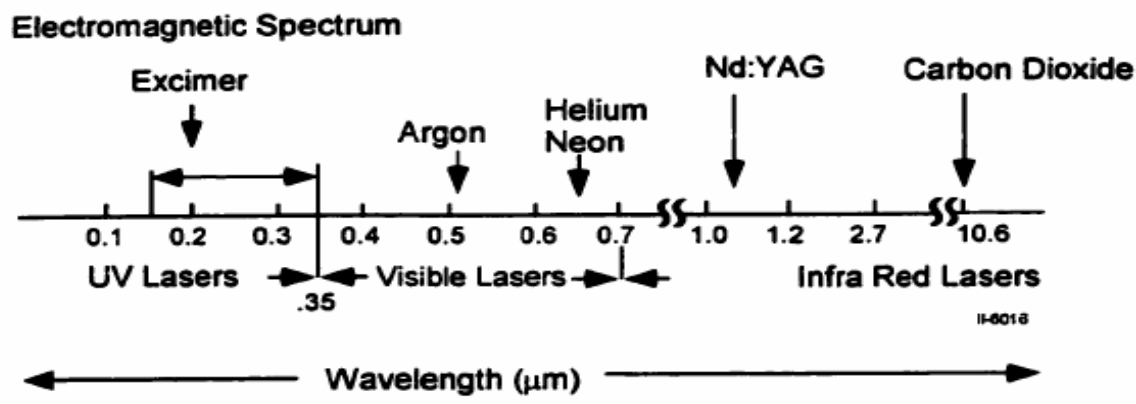

Figure 5. The wavelengths of different lasers in the electromagnetic spectrum

There are three types of lasers that are of sufficient energy and robustness that are used for surface treatment (Folkes, J., 1997) which are Carbon Dioxide (CO2) Laser, Neodymium-doped Yttrium Aluminum Garnet, (Nd:YAG) Laser and Excimer Laser. 
Figure 5 shows the location of some of the lasers in the electromagnetic spectrum (Folkes, 1994).

The carbon dioxide laser can be pulsed or continuous wave and ranges in power from typically 0 to $10 \mathrm{~kW}$. It has an output wavelength in the far infrared, in the region of $10.6 \mu \mathrm{m}$. This wavelength is relatively long so generally the surface modification occurs by heating effects. The energy density and interaction time between the laser and the substrate, as well as the ability of the surface to absorb this wavelength are the main factors that determine the resulting surface modification.

The Nd:YAG laser can be pulsed or continuous wave and ranges in power from 0 to $3 \mathrm{~kW}$. This output wavelength is $1.06 \mu \mathrm{m}$ which is shorter than the carbon dioxide laser but still in the infrared region. Thus, the surface modification occurs by heating effects, however coupling the laser radiation into the surface tends to be easier due to the shorter wavelength.

The Excimer laser is pulsed and ranges in energy from 0 to $600 \mathrm{~J}$. There are several different excimer lasers depending on which gas is used inside the system to achieve the laser action. The output wavelength is in the ultra violet region $(200 \sim 400$ $\mathrm{nm})$. These wavelengths are relatively short and generally the surface modification occurs by a combination of photon interaction and heating effects. Since the wavelength is short the surface interaction/coupling of the laser into the surface is paramount in understanding the process.

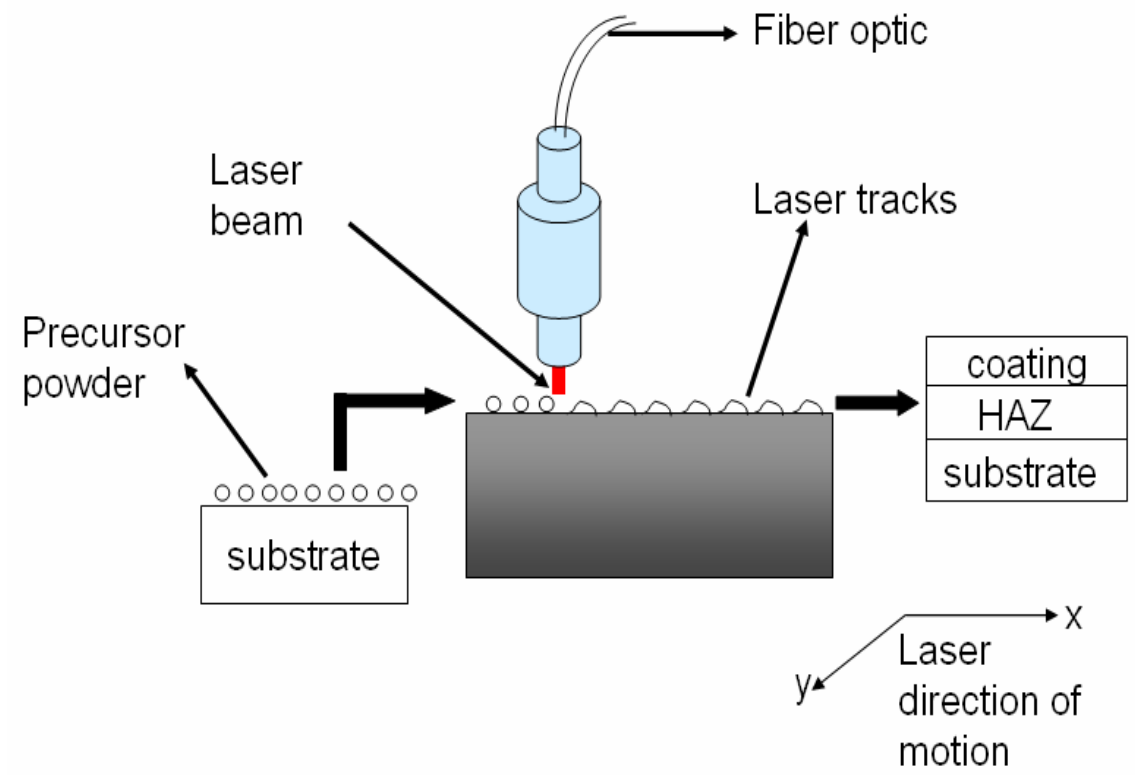

Figure 6. Schematic of the LSE process

Typical laser surface modification processes include (1) transformation hardening, (2) surface melting, (3) surface cladding, (4) surface alloying and (5) other techniques (surface smoothing, texturing, coating removal and micromachining, etc.). Due to the 
overlapping of the various laser surface modification processes, a new term "Laser Surface Engineering (LSE)" was proposed by Agarwal (1999) and therefore LSE was used in this proposal. A typical LSE process is schematically shown in Figure 6.

Laser surface engineering is known as a non-equilibrium synthesis involving high heating and cooling rates $\left(10^{3}-10^{8} \mathrm{~K} / \mathrm{s}\right)$, which leads to the development of a wide variety of microstructures with novel properties that can not be achieved by any conventional processing technique (Mazumder, 1996). Other features of laser surface engineering include (Dahotre, 1998):

- High coating thickness (up to $0.8 \mathrm{~mm}$ )

- Metallurgically bonded coating

- Non-equilibrium synthesis process leading to the development of novel phases

- Precise control of processing parameters

- Beam can be shaped for a variety of energy distributions

- High flux densities $\left(>10^{4} \mathrm{w} / \mathrm{cm}^{2}\right)$

- Laser beam transport to remote locations via fiber optics

- Allows for the processing of a wide variety of part configurations

- Amenable to automation 


\section{EXPERIMENTAL}

\section{Materials}

Two steels were selected as substrates in this research, which are AISI 4140 and ASTM A36, respectively. AISI 4140 is one of the chromium, molybdenum, manganese low alloy steels noted for high toughness, good tensile strength as well as high fatigue strength. It is widely used in fabrication of equipment used in the mineral processing industry. ASTM A36 is widely used for framing and general structural purposes to provide strength and stability. Also, the screen panels studied in this research are made of this steel. The chemical compositions of AISI 4140 and ASTM A36 are listed in Tables 1 and 2, respectively (Davis, 1998).

Table 1. Chemical compositions of the AISI 4140 steel (in wt.\%)

\begin{tabular}{ccccccccc}
\hline Element & $\mathrm{C}$ & $\mathrm{Mn}$ & $\mathrm{P}$ & $\mathrm{S}$ & $\mathrm{Si}$ & $\mathrm{Mo}$ & $\mathrm{Cr}$ & $\mathrm{Fe}$ \\
\hline \multirow{2}{*}{ Weight,\% } & $0.38-$ & $0.75-$ & 0.035 & 0.04 & $0.15-$ & $0.15-$ & $0.8-$ & Bal. \\
& 0.43 & 1.00 & $(\max )$ & $(\max )$ & 0.30 & 0.25 & 1.10 & \\
\hline
\end{tabular}

Table 2. Chemical composition of ASTM A36 steel (in wt. \%)

\begin{tabular}{ccccccc}
\hline Element & $\mathrm{C}$ & $\mathrm{P}$ & $\mathrm{S}$ & $\mathrm{Si}$ & $\mathrm{Cu}$ & $\mathrm{Fe}$ \\
\hline Weight, \% & 0.25 & 0.04 & 0.05 & 0.4 & 0.2 & Bal. \\
\hline
\end{tabular}

The mineral processing industry requires materials having strength, toughness, wear and corrosion resistance. It should be noted that coating steels using high energy process such as laser with ultrahard ceramic particles has been developed to meet the extreme requirements of wear, oxidation and corrosion resistance (Agarwal, 2000; Khedkar et al, 1997). As a result, metallurgically sound interface between the coating and the substrate can be formed. However, as the physical properties such as thermal expansion coefficient (CTE) between the ceramic and the steels usually are different, cracks usually develop at the ceramic/steel interface as well as within the coating during the rapid solidification and cooling progress (Agarwal et al., 2000). The use of binders in coating materials can promote the good adhesion between the coatings and the steel substrates. For example, iron has been revealed as an excellent binder for Ti-based coatings on steels (Raghunath et al., 1995).

Based on the experience accumulated by ORNL researchers, a range of coating materials were employed for the LSE process. In this report, LSE-processed coatings using Ti-based ceramics $\left(\mathrm{TiC}, \mathrm{TiB}_{2}\right)$ materials were introduced. A Nickel-Phosphorus binder was alloyed in house from powders supplied by Cerac (Milwaukee, WI). The 
coatings are denoted as (Ni-10P)-50TiC (wt\%) and (Ni-10P)-50 $\mathrm{TiB}_{2} \quad(\mathrm{wt} \%$ ), respectively. Besides, a raw coal screen panel was coated with Metco $12 \mathrm{C}$ self-fluxing alloy powder (Chromium, 10\%; Boron, 2.5\%; Iron, 2.5\%; Silicon, 2.5\%; Carbon, $0.15 \%$; and Nickel, Balance). This coated screen was used for in-plant test.

\section{Coating Preparation Using LSE}

\section{$\underline{\text { Sample-Pretreatment }}$}

Test samples (AISI 4140 steel and ASTM A36 steel) were cut to a suitable size (3" $\times 3$ ") for coating preparation. Each specimen was pre-treated prior to coating preparation. This involves removing any grit stuck in the sample surface by using grit blasting and wire brushing. The sample then was wiped down with acetone to remove any residual oils etc. followed by rinsing with alcohol to remove the residual from the acetone.

\section{Coating Preparation}

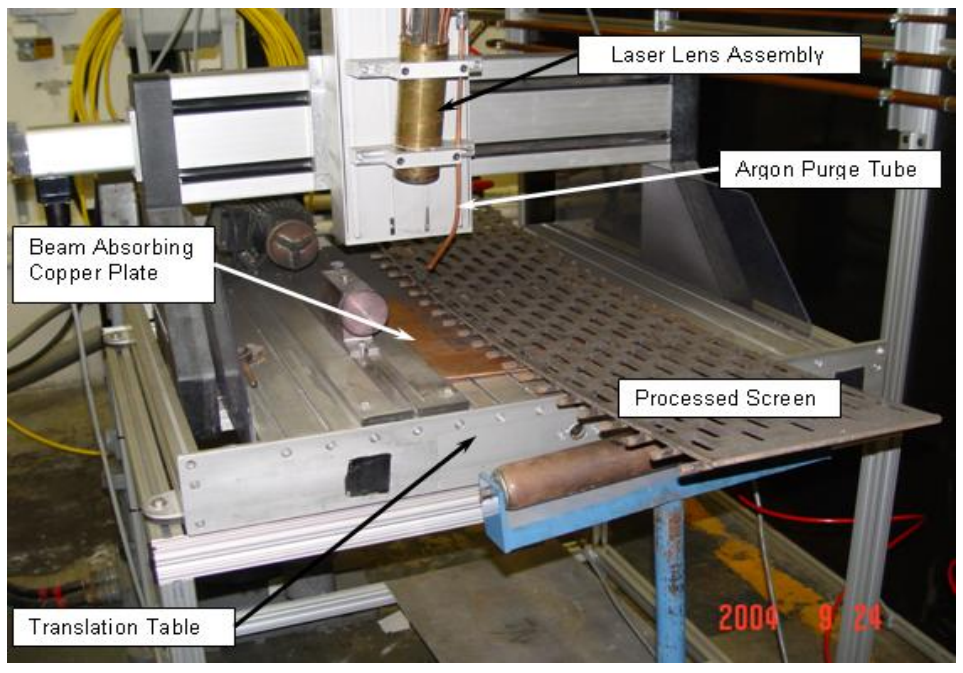

Figure 7. Experimental set-up for laser coating

A $4 \mathrm{~kW} \mathrm{Nd:YAG} \mathrm{laser} \mathrm{equipped} \mathrm{with} \mathrm{a} \mathrm{flexible} \mathrm{fiber-optic} \mathrm{beam} \mathrm{delivery} \mathrm{system}$ was employed for the synthesis of the coatings. The lens assembly was configured to provide an elliptically shaped beam ( $\sim 2 \mathrm{~mm}$ minor axis and $\sim 6 \mathrm{~mm}$ major axis) onto the sample surface. An argon cover gas was introduced to minimize the oxidation of the substrate and coating materials. A copper plate was put under the sample to absorb any stray laser radiation. Figure 7 shows a raw coal screen panel $\left(4^{\prime} \times 1^{\prime}\right)$ being processed using the LSE facility at ORNL.

There are two major parameters for a laser surface coating process, which are laser beam power and traverse speed. In the past year, a considerable amount of tests were designed and performed to find the "ideal" LSE-treated coating. For the 
convenience of presentation, a reduced dataset was reported in this report. This includes the test results from 8 typical coupons including 4 AISI 4140 steel coupons denoted as C1 to $\mathrm{C} 4$, and 4 ASTM A36 steel coupons (S1-S4), i.e., raw coal screen sections. For the purpose of comparison, an untreated AISI 4140 and an ASTM A36 coupon were also involved. The processing parameters of each specimen are listed in Tables 3.

Table 3. Coating processing conditions

\begin{tabular}{ccccc}
\hline ID & Power, $\mathbf{W}$ & $\begin{array}{c}\text { Speed, } \\
\mathbf{m m} / \mathbf{m i n}\end{array}$ & Substrate & Coating \\
\hline C-1 & 1500 & 1500 & AISI 4140 & \\
C-2 & 1500 & 1750 & AISI 4140 & (Ni-10P)-50TiC \\
S-1 & 1500 & 1500 & Screen & \\
S-2 & 1500 & 1750 & Screen & \\
\hline C-3 & 1250 & 1500 & AISI 4140 & \\
C-4 & 1500 & 1500 & AISI 4140 & (Ni-10P)-50TiB 2 \\
S-3 & 1250 & 1500 & Screen & \\
S-4 & 1500 & 1500 & Screen & \\
\hline
\end{tabular}

\section{Sample Characterization}

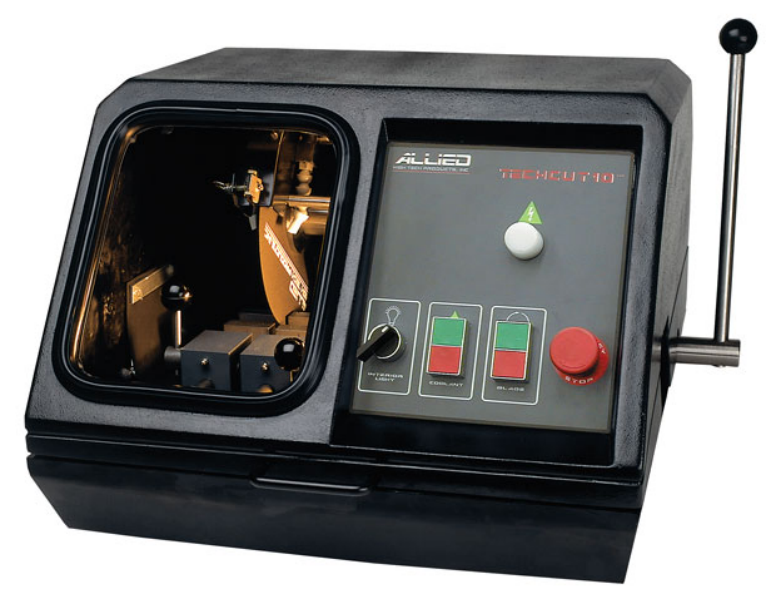

Figure 8. Allied TechCut10 ${ }^{\mathrm{TM}}$ Abrasive Cut-Off Saw

The characterization work is to investigate the mechanical, microstructural as well as tribologcial properties of processed specimens. The scope of microstrural characterization includes observation the bonding of the coating/substrate interface, phase distribution in the coating system. The specimens were cut from each sample by Allied TechCut10 ${ }^{\mathrm{TM}}$ Abrasive Cut-Off Saw (Figure 8). The specimens were then mounted using epoxy resin with cross-section of coating-substrate interface exposed outside. The resin mounted specimen was easy to handle and ensured that the exact cross-section surface should be polished. The mounted specimens were polished by mechanical grinding with a series of sand papers from coarse to fine (labeled with the following numbers: 200, 400, $600,800,1000$ and 1200 grits). The purpose of this procedure was to remove the 
damages produced during cutting process. After the specimens were ground over the finest sand paper, the final step was to finish up on a polishing cloth with $0.3 \mu \mathrm{m}$ alumina paste to obtain scratch free surfaces. This step was to remove any scratches or damage generated by the grinding. Figure 9 shows a typical prepared specimen for microstructure examination.
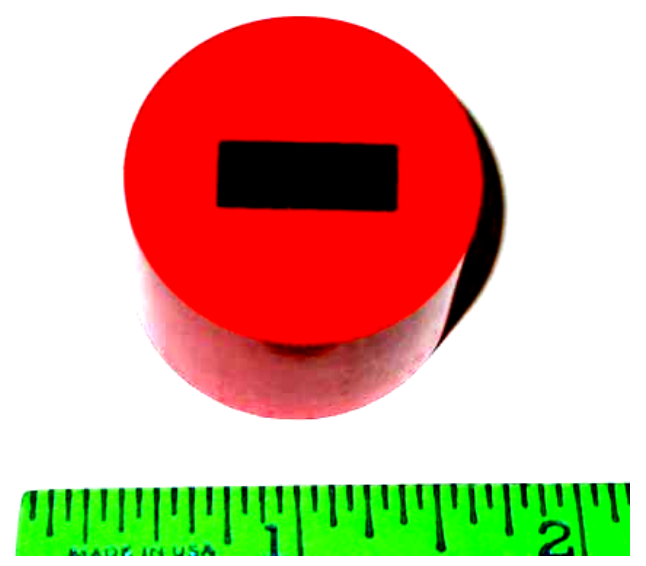

Figure 9. A typical specimen prepared for SEM study

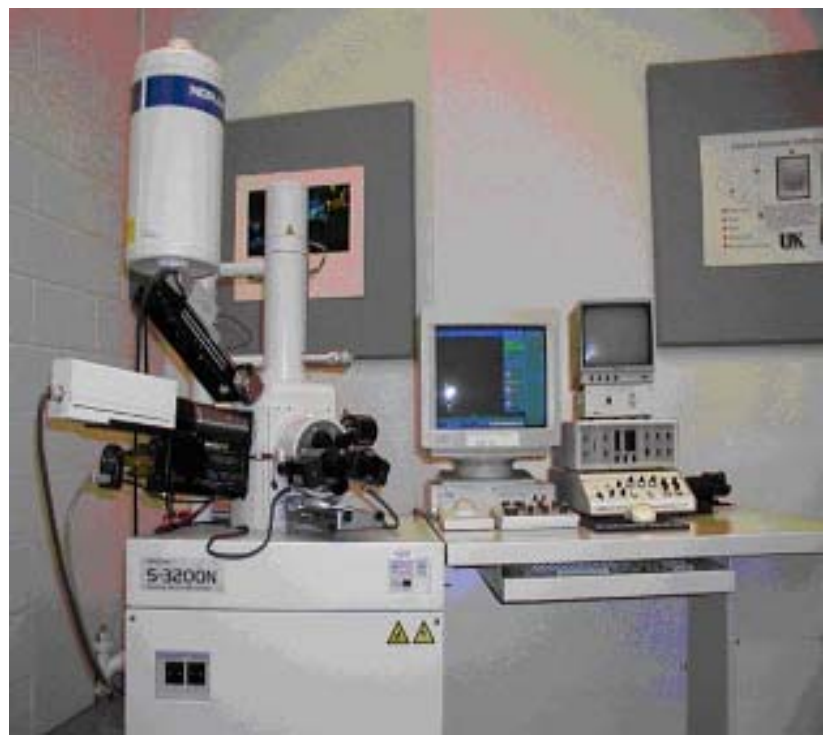

Figure 10. Hitachi S-3200 SEM

The scratch free specimen surfaces were then etched to reveal the grain structure of the metallic phases. $2 \%$ Nital $(98 \mathrm{ml}$ ethanol $+2 \mathrm{ml}$ nitric acid) was used as the etchant. The etchant did two things to the specimen surface. First, it chemically removed the deformed thin layer on the surface which was produced during the polishing process. Second, the etchant selectively attacked the highest energy sites on the surface without affecting the others. As a result, different crystal orientations, grain boundaries, 
precipitates, phases and defects were showed distinctly under the microscopy for the microstructure investigation. A Hitachi S-3200 scanning electron microscope (SEM, Figure 10) equipped with energy dispersive spectroscopy (EDS) was employed to perform the microstructural characterization. An X-Ray Diffractometer (Siemens D-500, Figure 11) was used for the phase identification of processed surface coatings.

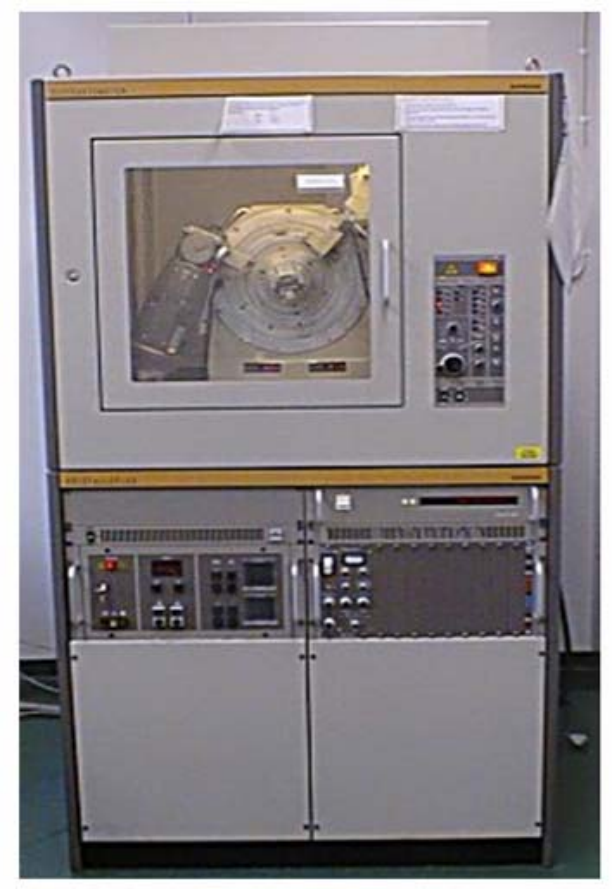

Figure 11. Siemens D-500 X-Ray Diffractometer

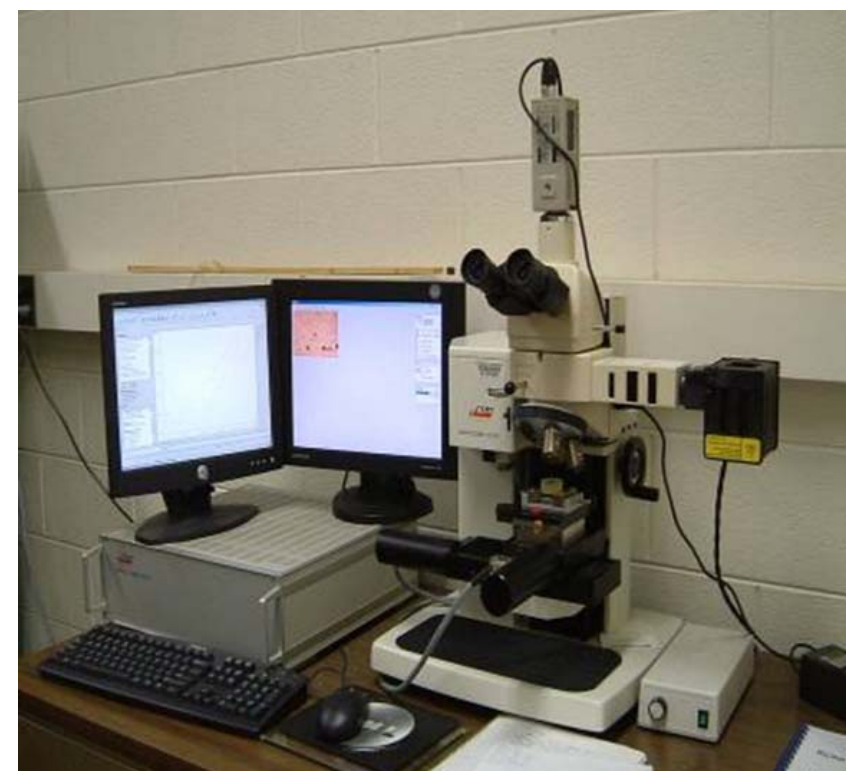

Figure 12. Microindentation tester 
The mechanical properties was be examined by microindentation from which coating hardness profile can be achieved. Microindentation behavior of the coating and substrate will be studied at different loads. Figure 12 shows the indentation instrument (Micro Photonics, Irvine, CA) used in this research.

The wear resistance of LSE-treated specimens was tested in lab using an in-house constructed block-on-ring wear test machine (Figure 13). Each coated specimen will be slid against a hardened tool steel ring $(H R C \approx 60, D=82 \mathrm{~mm})$. The ring's rotating speed is controlled at $1000 \pm 20 \mathrm{rpm}$. Specimen weight loss was measured after each successive 2 minutes for a total test duration of 20 minutes. A normal load of $10 \mathrm{lbs}(4.54 \mathrm{~kg})$ was applied on the specimen during the test.

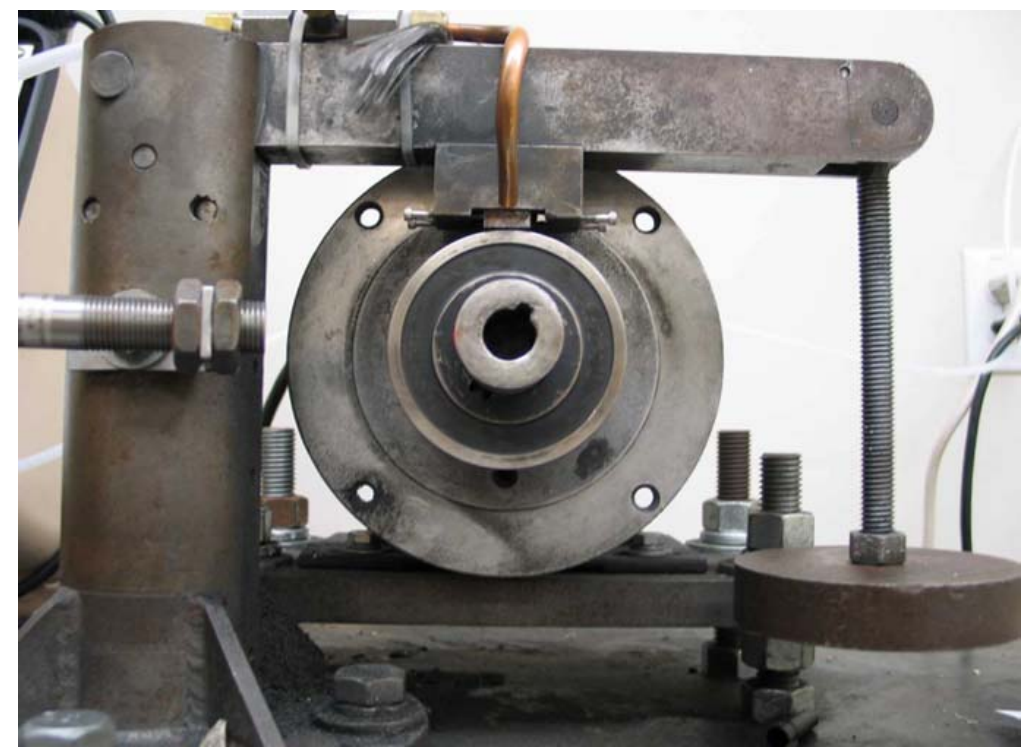

Figure 13. Block-on-ring tribometer

\section{On-site Testing}

This task has been performed ahead of schedule to expedite the progress of the project as well as to accommodate our industrial supporters' enthusiasm and thirst for new technology. Coated raw coal screen panels were installed at the Big Creek Processing Plant (Sidney, KY) of Sidney Coal Company Inc. The raw coal screen panels provided by Sidney Coal were made of ASTM A36 steel with a dimension of $1.21 \mathrm{~m} \times$ $0.3 \mathrm{~m} \times 6 \mathrm{~mm}$. The aperture size of the panel is $50 \mathrm{~mm} \times 13 \mathrm{~mm}$. Big Creek Processing Plant is a coal preparation operation with a processing capacity of 12 Mt raw coal annually. The Plant uses two screens for raw coal sizing process, each consisting of 40 panels (Figure 14). This screen panel was processed by Nd:YAG laser (2000 W, 1500 $\mathrm{mm} / \mathrm{min}$ ) with Metco $12 \mathrm{C}$ coating. 


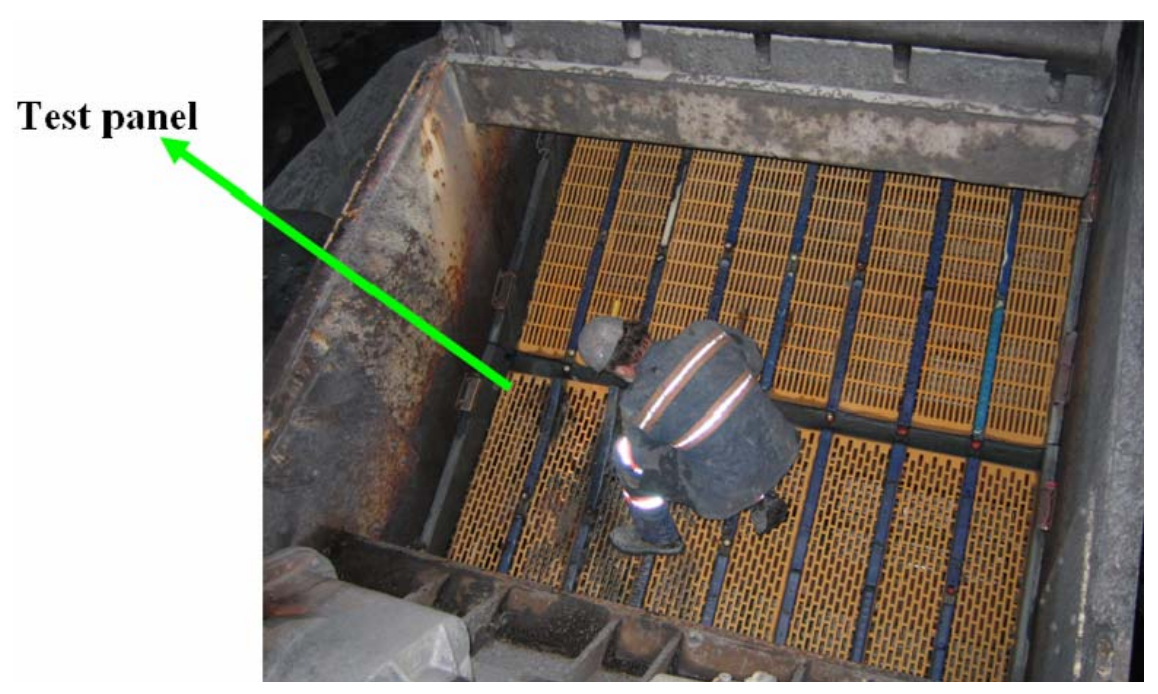

Figure 14. On-site test of coated screen panels

The test panel was put on the high-wear position of one of the two raw coal screens in the plant. One screen handles around $800 \mathrm{ton} / \mathrm{hr}$ raw coal. The screen operates 24 hours/day, and the plant is shut down 12 hour for maintenance every week. Weight and opening size variations of the test panel were measured every other week. 


\section{RESULTS AND DISCUSSION}

\section{LSE-treated Samples}

Figures 15, 16 provide a typical LSE-treated AISI 4140 steel coupon and a coated screen section, respectively. The coupon showed a resultant texture of typical laserprocessed surface with laser tracks on.

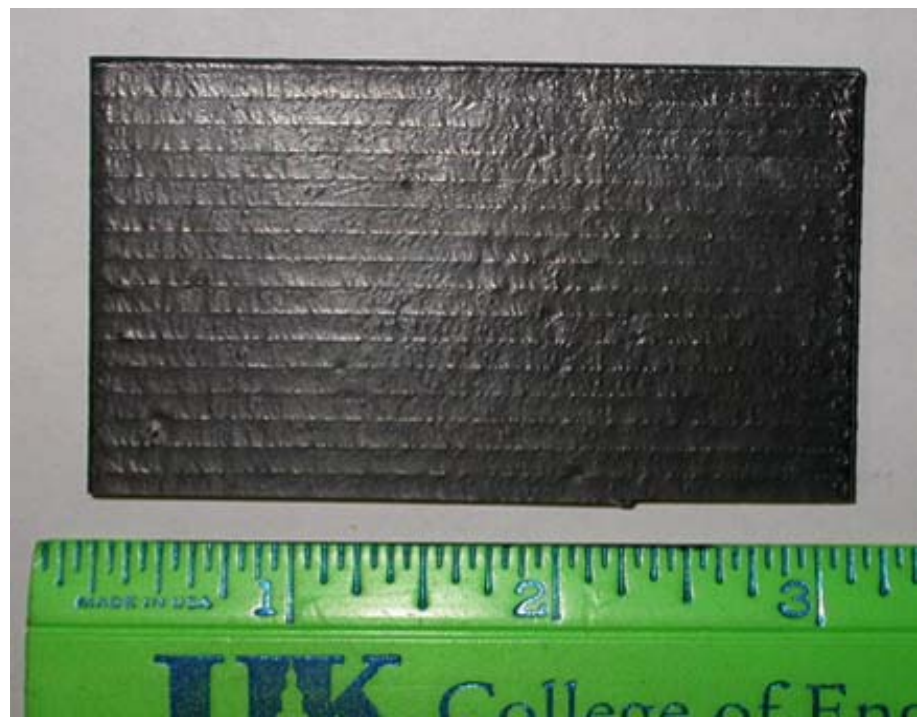

Figure 15. AISI 4140 coupon with (Ni-10P)-50TiB 2 coating

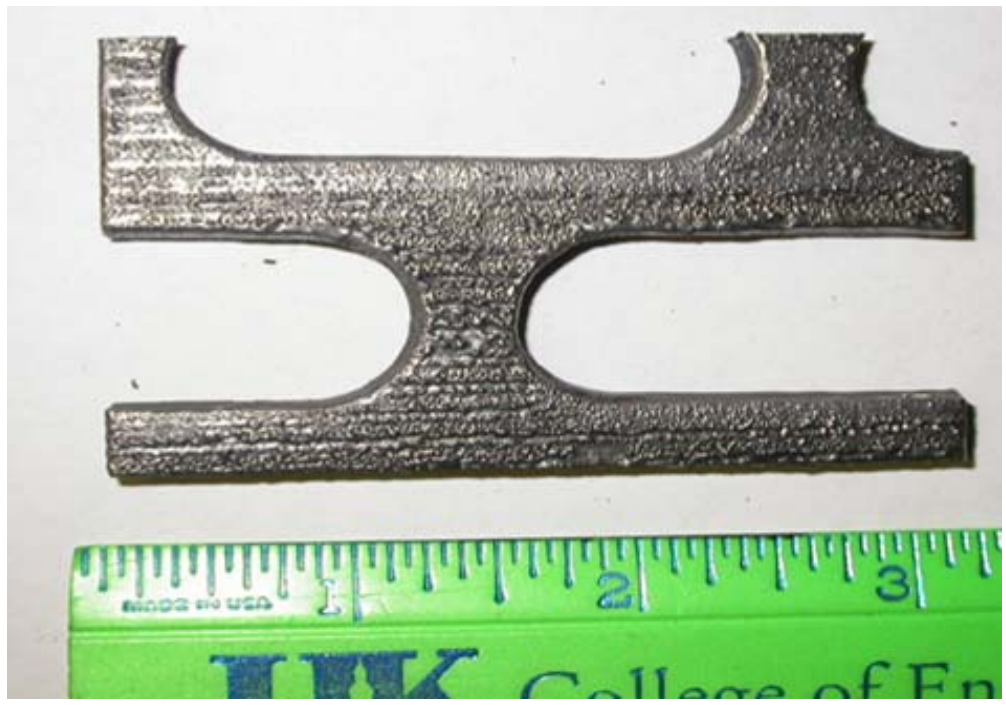

Figure 16. Screen section with (Ni-10P)-50TiC coating

Figure 17 shows the picture of a coated screen panel used for in-plant testing. Compared to the screen sections or AISI 4140 coupons, this screen panel has a much larger dimension indicating the capability of processing large component of the LSE unit. 
The direction of the laser tracks was set parallel to that of the coal flow, which was believed to help to decrease the friction between coal particles and the screen surface.

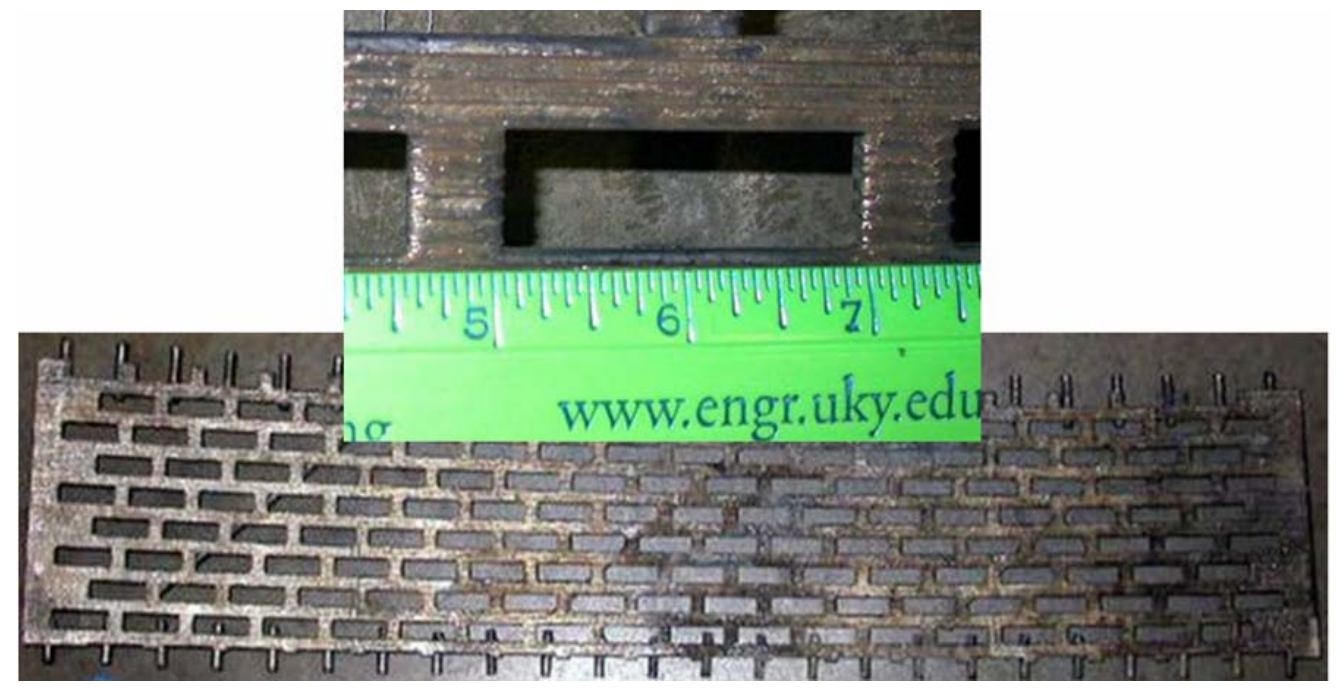

Figure 17. Coated screen panel for on-site testing

\section{Microstructure}

Optical Microscopic Studies

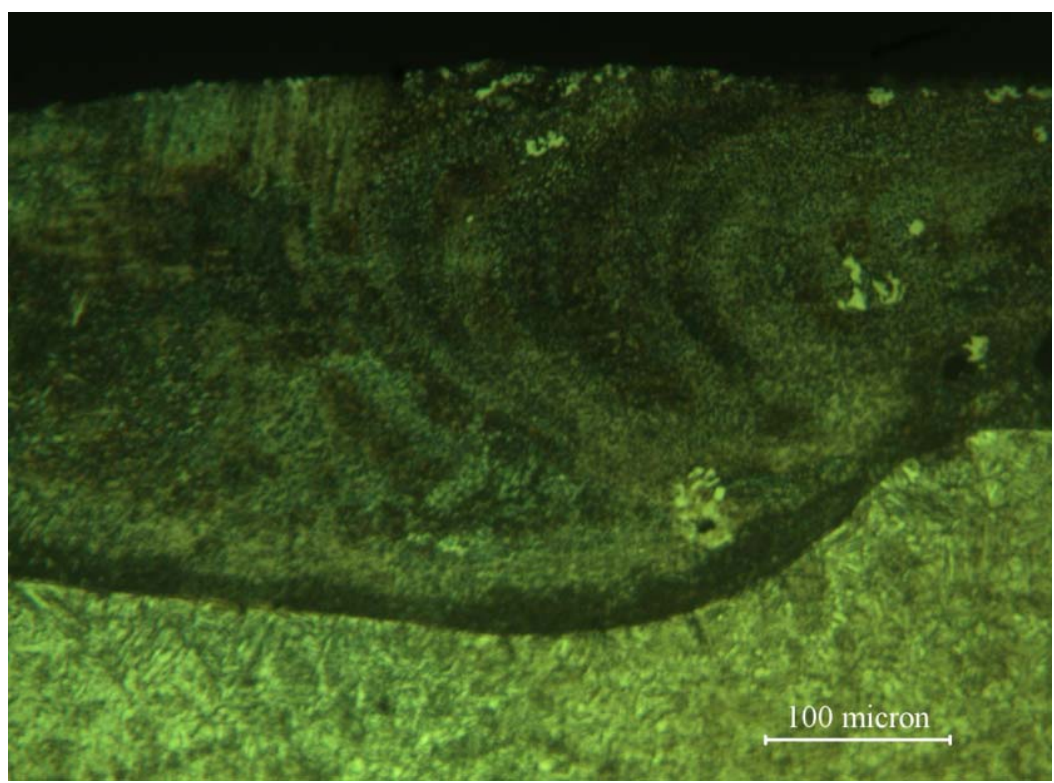

Figure 18. OM image of Sample S3

The coated samples were imaged crossectionally by using optical microscope. Figure 18 shows a typical OM image obtained on Sample S3 (Screen section, (Ni-10P)$\left.50 \mathrm{TiB}_{2}\right)$. It can be seen that a uniform coating layer was formed on the substrate and the coating thickness is about 150 - $200 \mu \mathrm{m}$, depending on the location of measurement, i.e., 
thicker coating is formed at the location where two adjacent tracks overlaps, which results in more heat flow into the substrate, increasing the depth of laser affected zone. Figure 18 also demonstrates the convention pattern of the LSE process. During laser surface coating process, due to the high temperature generated by laser a melting pool is formed which includes both coating precursor powder and materials from the surface of treated surface. This allow the material transportation possible, e.g., it will be shown in the following section that iron from the substrate was transferred to the coating layer due to this convection effect.

Careful examination of the coating/substrate interfacial area indicates that there exists a clear microstructure evolution from coating, HAZ (Heat Affected Zone) to substrate, as shown in Figure 19. The presence of HAZ induces mechanical and structural modifications around the laser scanning area as well as the coating properties.

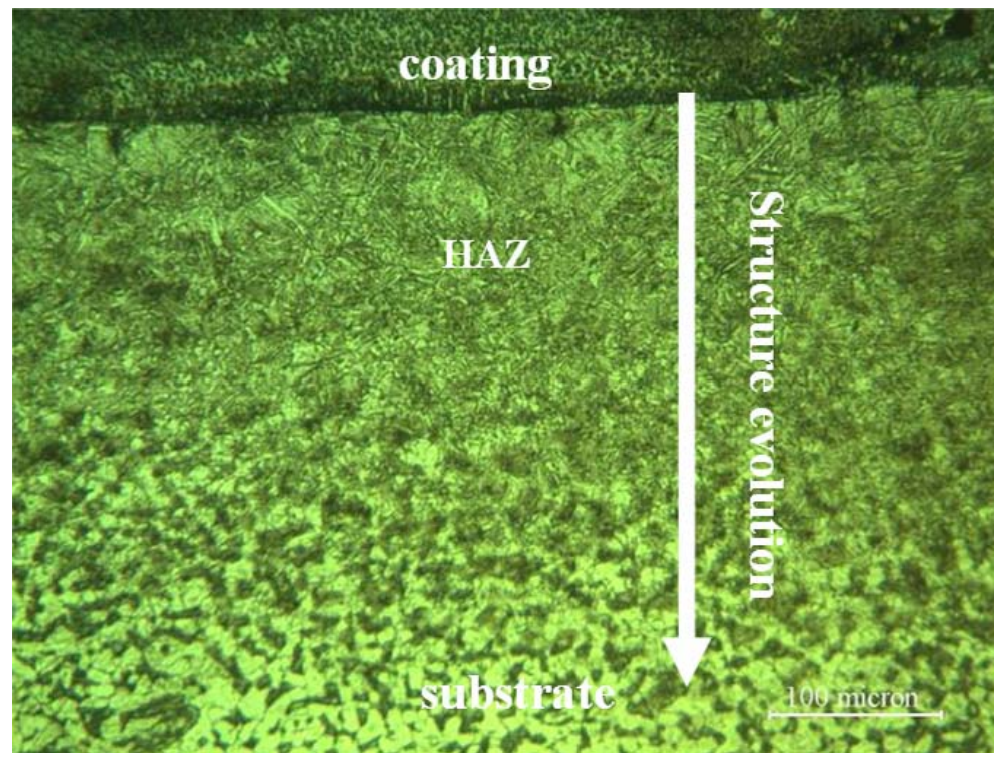

Figure 19. Microstructure evolution of the coated sample

\section{$\underline{\text { SEM Characterization }}$}

To further investigate the microstructures of coatings and substrates, SEM examinations were carried out. The cross section SEM morphologies of Sample C1 and C3 are shown in Figures 18 and 19, respectively. It can be seen from each SEM image that there are three regions marked as coating, interface (or heat affected zone) and substrate. The presence of heat affected zone with certain depth proved that the coatings were metallurgically bonded to the substrates. Generally, poor bonding between coating and substrate always degrades the coating adhesion strength. As a result, the coating may detach easily from the substrate, damaging its mechanical and tribological performance. The strong metallurgical bonds are known to significantly increase the coating-substrate adhesion strength. 
A close-up of the coating layer suggests that $\mathrm{TiC} / \mathrm{TiB}_{2}$ particles distribute uniformly in the coating area. The coating overall coating hardness can be increased by the presence of uniformly distributed Ti-based hard ceramics.

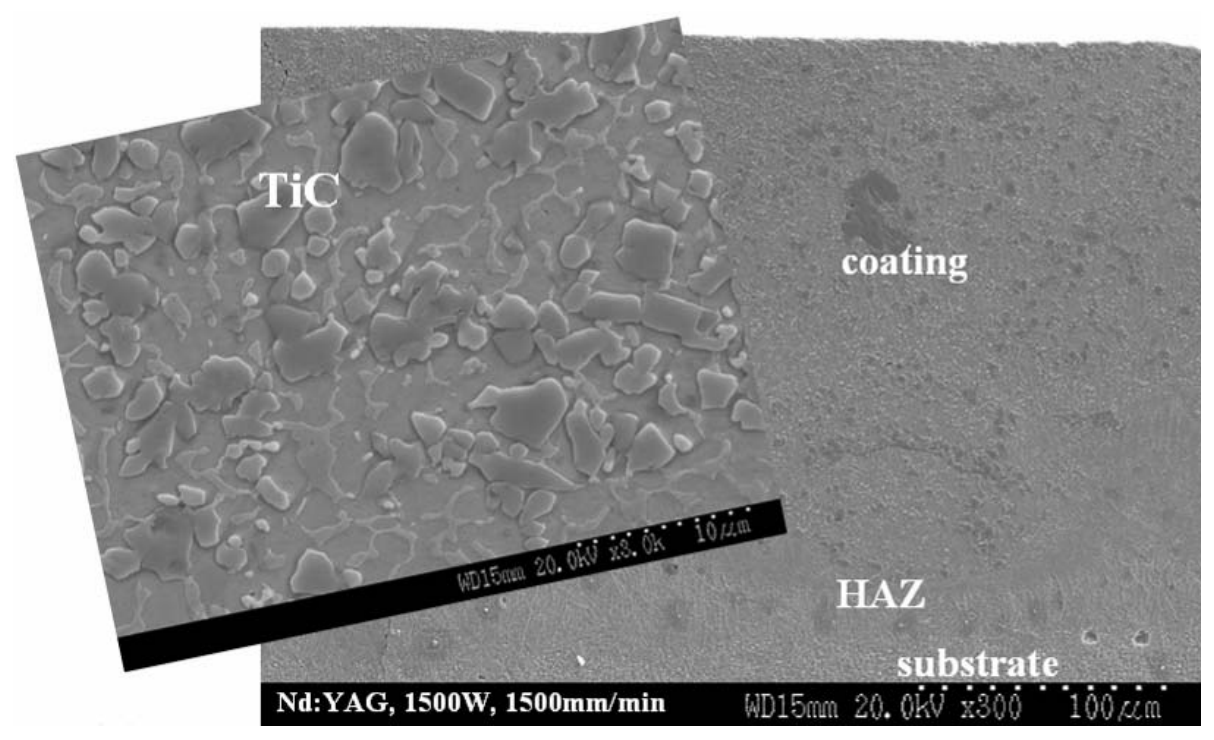

Figure 20. SEM image of Sample C1

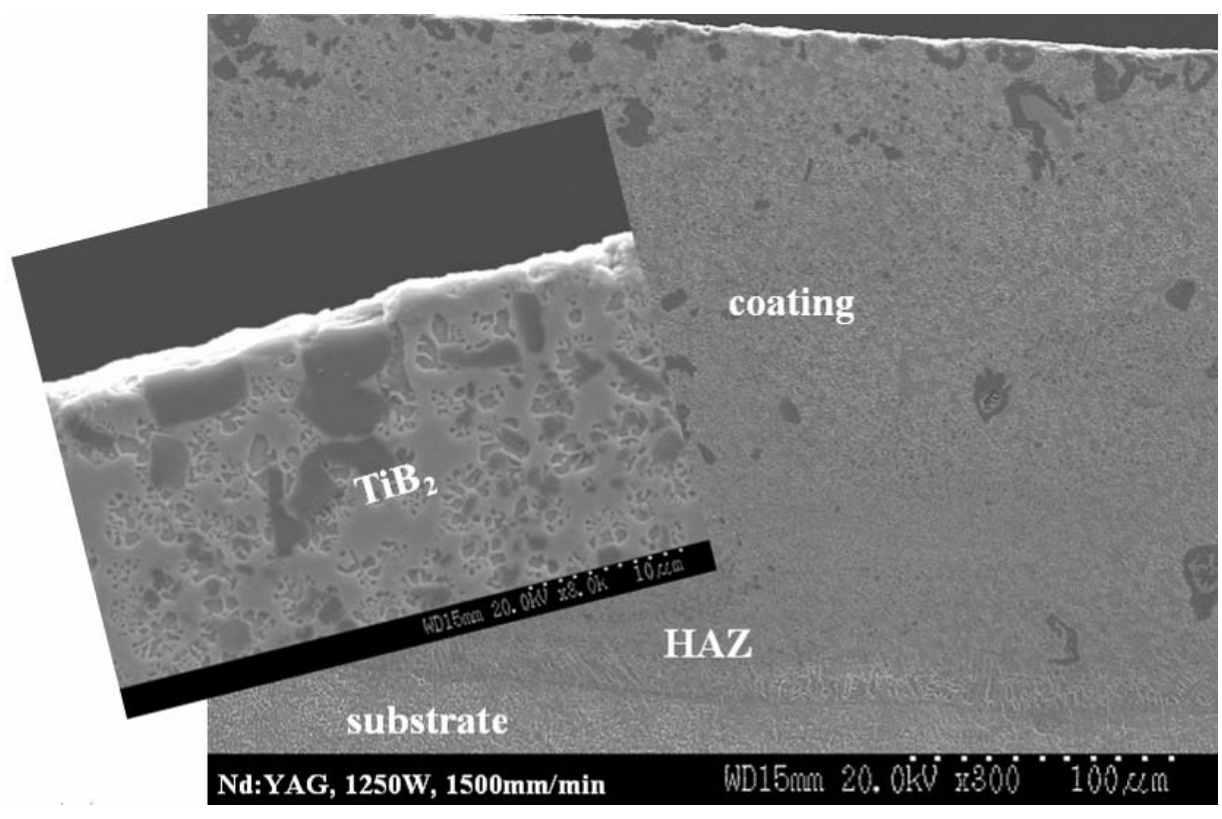

Figure 21. SEM image of Sample C3 


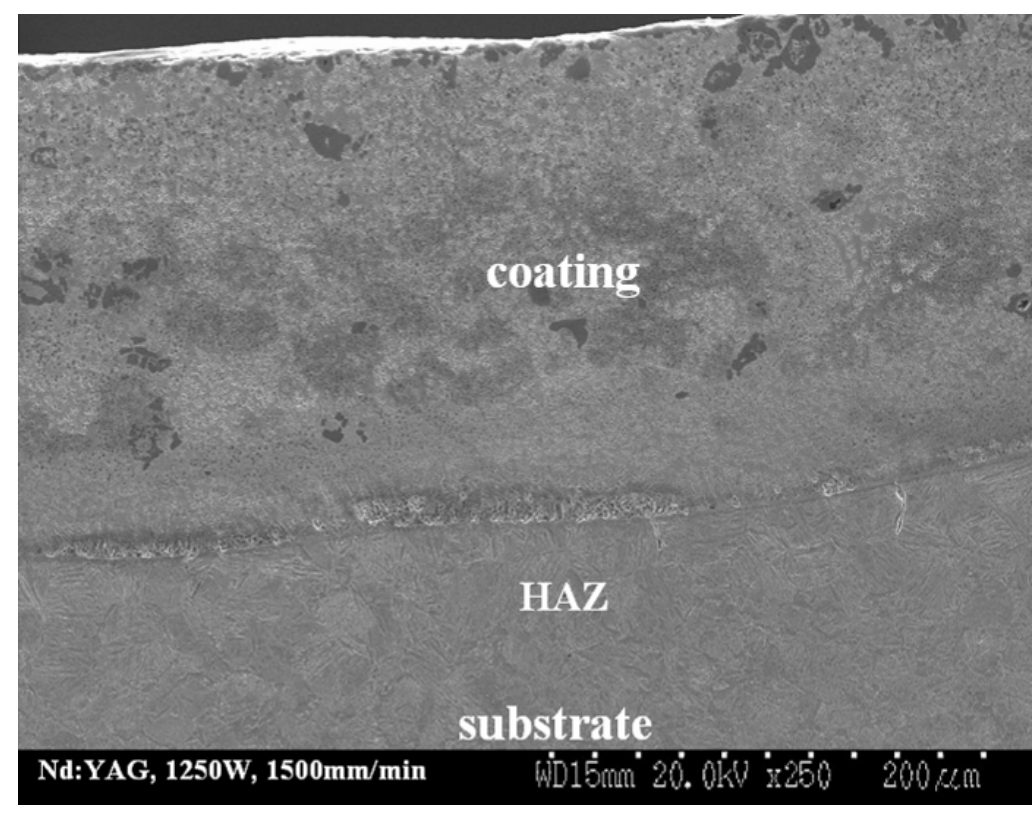

Figure 22. SEM image of Sample S3 (Overview)

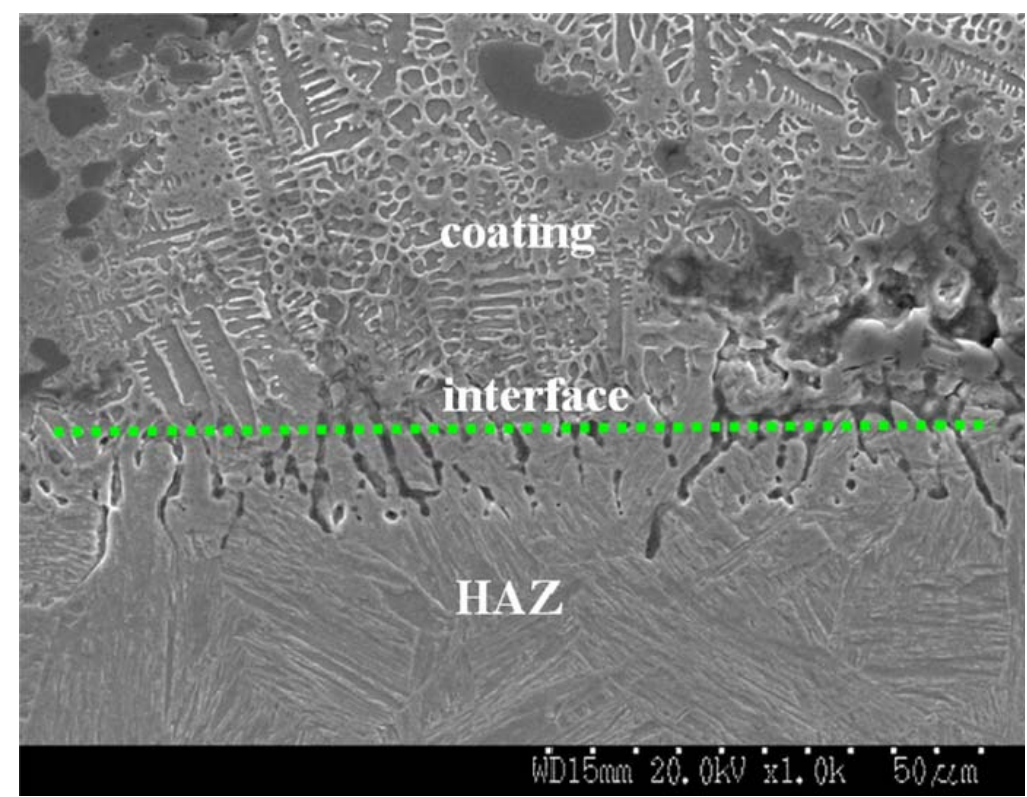

Figure 23. SEM image of Sample S3 (Interfacial area)

Also, similar observation was obtained on the coated screen sections, e.g., Figure 22 provides the SEM image made on Sample S3 which is a coated screen section with (Ni-10P)-50TiB 2 coating. A uniform and crack-free coating was obtained with a metallurgically sound interface, indicating the good wetting of the substrate by the coating. It should be mentioned that the coefficients of thermal expansion (CTE) of TiB2 and ASTM A36 steel are $6.39 \times 10^{-6} / \mathrm{K}$. and $6.5 \times 10^{-6} / \mathrm{K}$, respectively. The close CTE 
values of the two materials contribute to the formation of a uniform $\mathrm{TiB}_{2}$ coating on ASTM A36 steel during the laser treatment and result in much lower residual stresses in the finished product.

The SEM mircrograph of the coating-substrate interface of Sample S3 is showed in Figure 23. The presence of a continuous interfacial region indicates the coating was metallurgically bonded to the substrate. Coatings with this structure are expected to perform in a superior manner for wear applications as the chances of the coating delaminating are significantly reduced. The dendritic growth into the coating and martensite structure were observed in the interfacial region. This can be attributed to the rapid heating and cooling rates of the laser coating process (Agarwal and Dahotre,1999). It can be speculated that due to the high temperature attained in the laser treatment, the steel in the interfacial region can complete austenitization and transform to martensite, as shown in Figure 23.

\section{EDS Measurements}

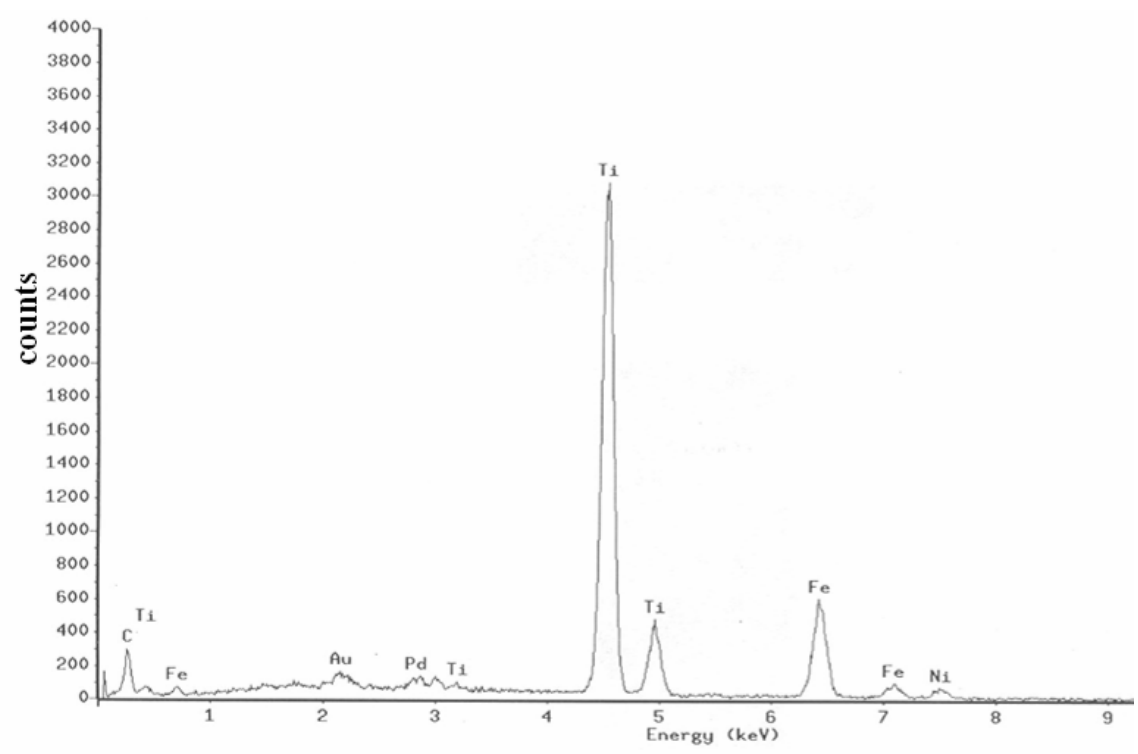

Figure 24. EDS spectrum of Sample C1 (Near coating surface)

Due to the fact that most coatings are not homogenous in nature, esp. after treating by high energy processes such as LSE, therefore, the chemical compositions detected by EDS at different positions are usually different. For example, Figure 24 gives the EDS spectrum taken near the coating surface of Sample C1. High amount of Ti was detected in this area. However, the amount of Ti element decreases along the coating depth. EDS measurements taken near the coating/substrate interface zone present much lower Ti\% but significant amount of $\mathrm{Fe}$, as shown in Figure 25. 


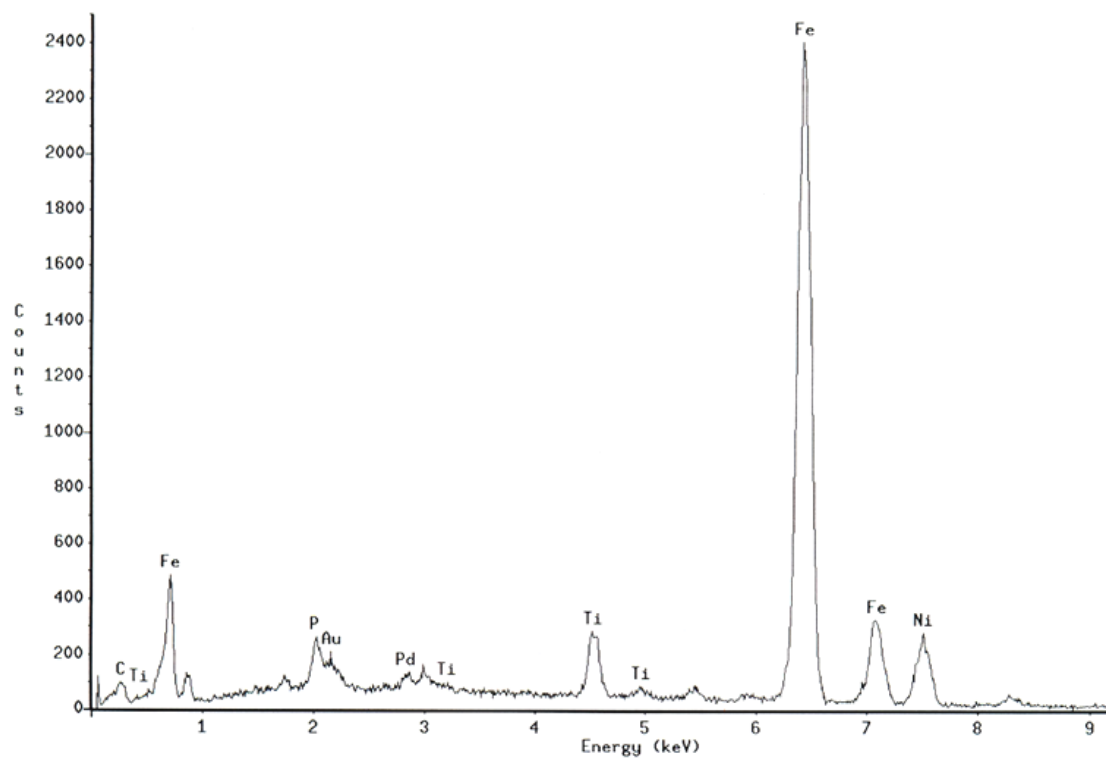

Figure 25. EDS spectrum of Sample C1 (Near interface zone)

Another interesting phenomenon is Fe was detected in the coating layer, as demonstrated in Figure 24. However, Fe was not included in the precursor powder before coating processing. The explanation for the presence of Fe element in coating matrix is that Fe from the substrate diffused in the coating. During the LSE process, the coating became liquid when fused by the laser. A thin layer of substrate materials melted due to the high temperature and Fe diffused from the substrate to the coating. Some Fe transferred to the up portion of the coating layer due to the convection effect discussed earlier.

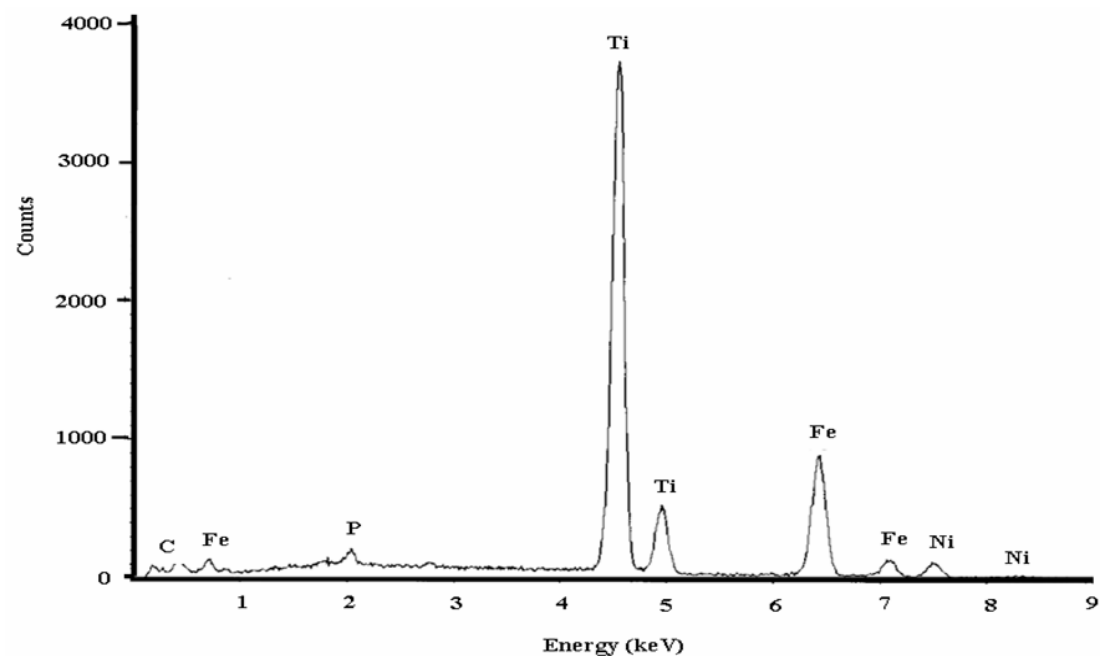

Figure 26. EDS spectrum of Sample S3 (Near coating surface) 


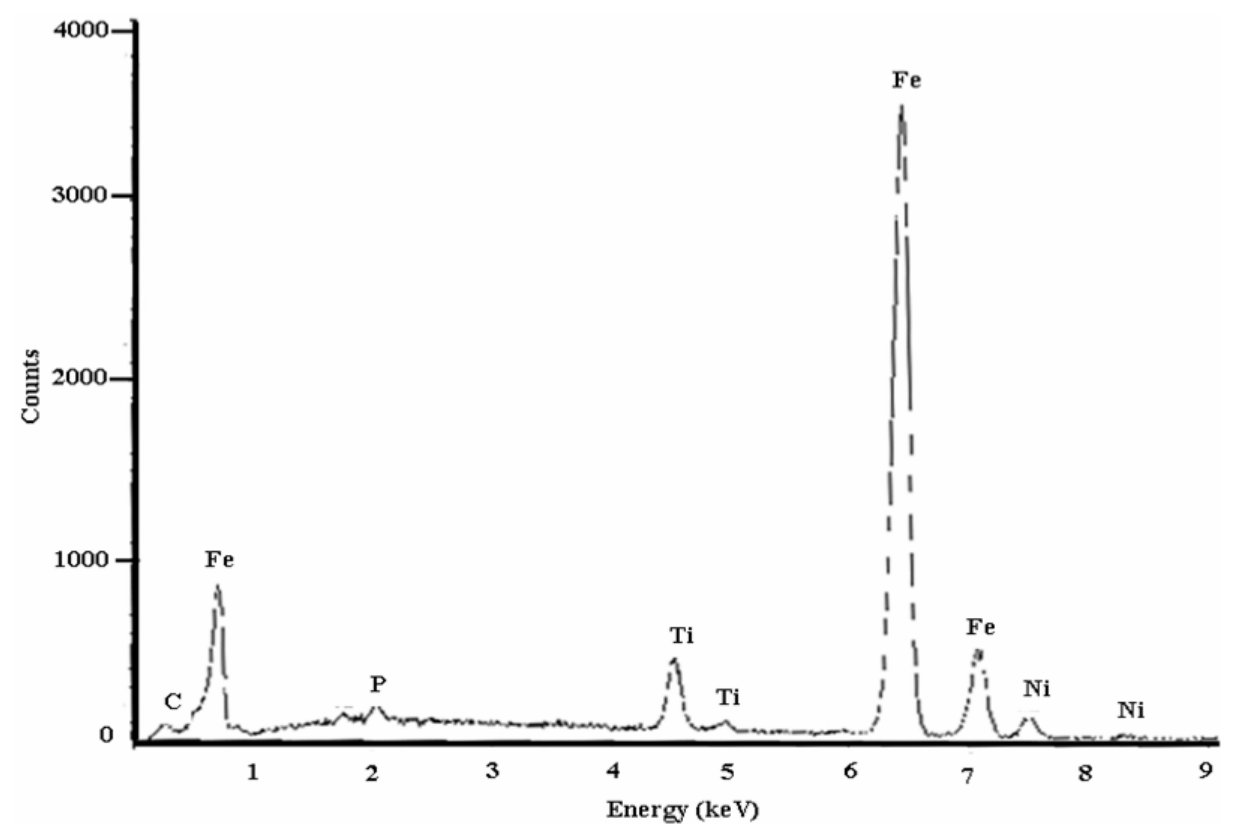

Figure 27. EDS spectrum of Sample S3 (Near interface zone)

EDS tests were also performed on the coated screen sections and similar results were also observed. For example, higher amount of $\mathrm{Ti}$ was found near the coating surface whilst higher Fe was detected near the coating/substrate area, as shown in Figures 26 and 27.

\section{$\underline{\text { XRD Characterization }}$}

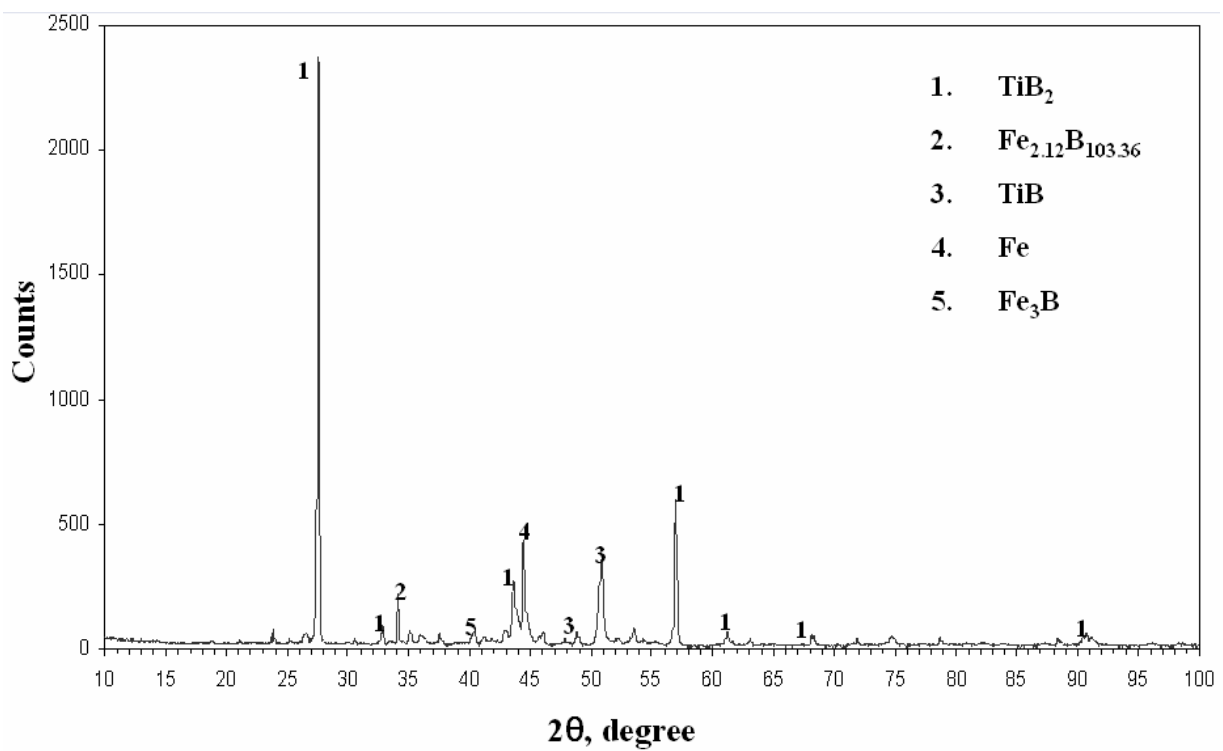

Figure 28. XRD spectrum of Sample S4 
X-ray diffraction was used for phase identification of the coated surfaces. Similar XRD spectra were obtained for the tested coupons. The XRD spectrum for Sample S4 is shown in Figure 28. It is observed that $\mathrm{TiB}_{2}$ is the most prominent phase in the coating. However, there exist several other peaks which confirm the formation of new phases during LSE process. The formation of new phases is believed to be due to reaction of $\mathrm{Fe}$ with the coating materials under the condition of high energy density of LSE process (Agarwal, 1999).

Guo and Derby (1998) have explained the formation of TiB by the follow reaction,

$$
\mathrm{TiB}_{2}+\mathrm{Ti}=2 \mathrm{TiB}
$$

This suggests that under some conditions $\mathrm{TiB}_{2}$ has dissociated and then recombined to form TiB. Excess boron could react with Fe to form metastable phases in the form of $\mathrm{Fe}_{\mathrm{x}} \mathrm{B}_{\mathrm{y}}$ as shown in Figure 28. In the meantime, some peaks were unidentified with existing powder diffraction data files. Further work needs to be done to probe the new phases in the following research period.

\section{Microhardness}

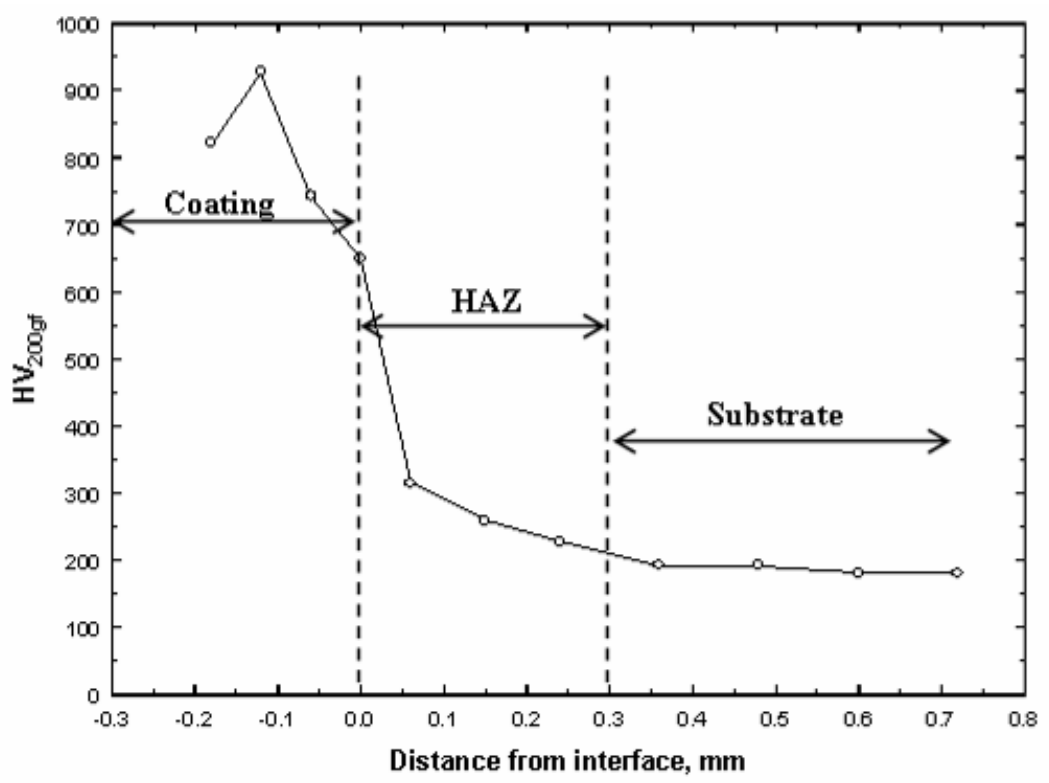

Figure 29. Microhardness profile of Sample S3

The microhardness tests were performed with a Vickers microhardness tester. The Vickers hardness values were calculated using the load and the diagonal length of the indent. Figure 29 provides the microhardness profile of Sample S3. The Vickers hardness profile of the specimen is depicted in Figure 29. One can see that there is a gradual decrease in microhardness values from the coating to the substrate. The average coating hardness is around $830 \mathrm{HV}$, whereas it deceases to $185 \mathrm{HV}$ in the substrate. The average microhardness at the interfacial and the heat-affected-zone (HAZ) is $300 \mathrm{HV}$ and 
$235 \mathrm{HV}$, respectively. $\mathrm{TiB}_{2}$ is a hard material. The microhardness of pure $\mathrm{TiB}_{2}$ is about $3200 \mathrm{HV}$ (Cutler, 1995), whereas the coating micronhardness values obtained in the present study are significantly lower than that. This is mainly because the coating is composite in nature. Other possibilities include the formation of additional phases. For example, as stated earlier, $\mathrm{Fe}$ from the substrate and $\mathrm{B}$ can exist in the form of $\mathrm{Fe}_{\mathrm{x}} \mathrm{B}_{\mathrm{y}}$ which has a lower microhardness than $\mathrm{TiB}_{2}$. Therefore, microhardness indentations obtained in this study basically represented the average hardness of the different phases. Further investigation, such as nanoindentation and TEM, can provide a more precise measurement of the hardness of individual phases. All the other test samples also presented a similar hardness profile and they will not be depicted here.

The Vickers indentations made during the microhardness measurements were imaged and one example is shown in Figure30. It can be clearly seen that the size of indentations in the coating is much smaller than that on the interface and in the substrate, which is in agreement with the microhardness data. Careful examination of the indentation on the interface also shows that no crack initiation or propagation is seen, indicating the high cohesive strength of the coating/substrate interface. This bonding strength can be further quantified using bending tests.

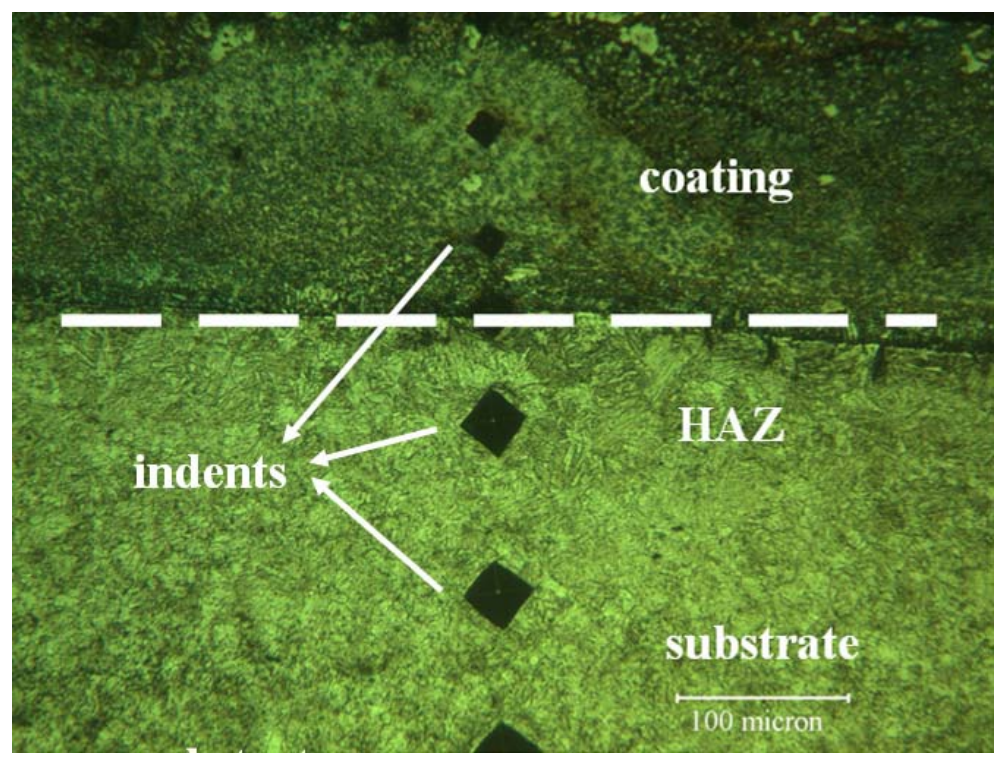

Figure 30. Image of microindentions (Sample S3) 


\section{Wear Testing}

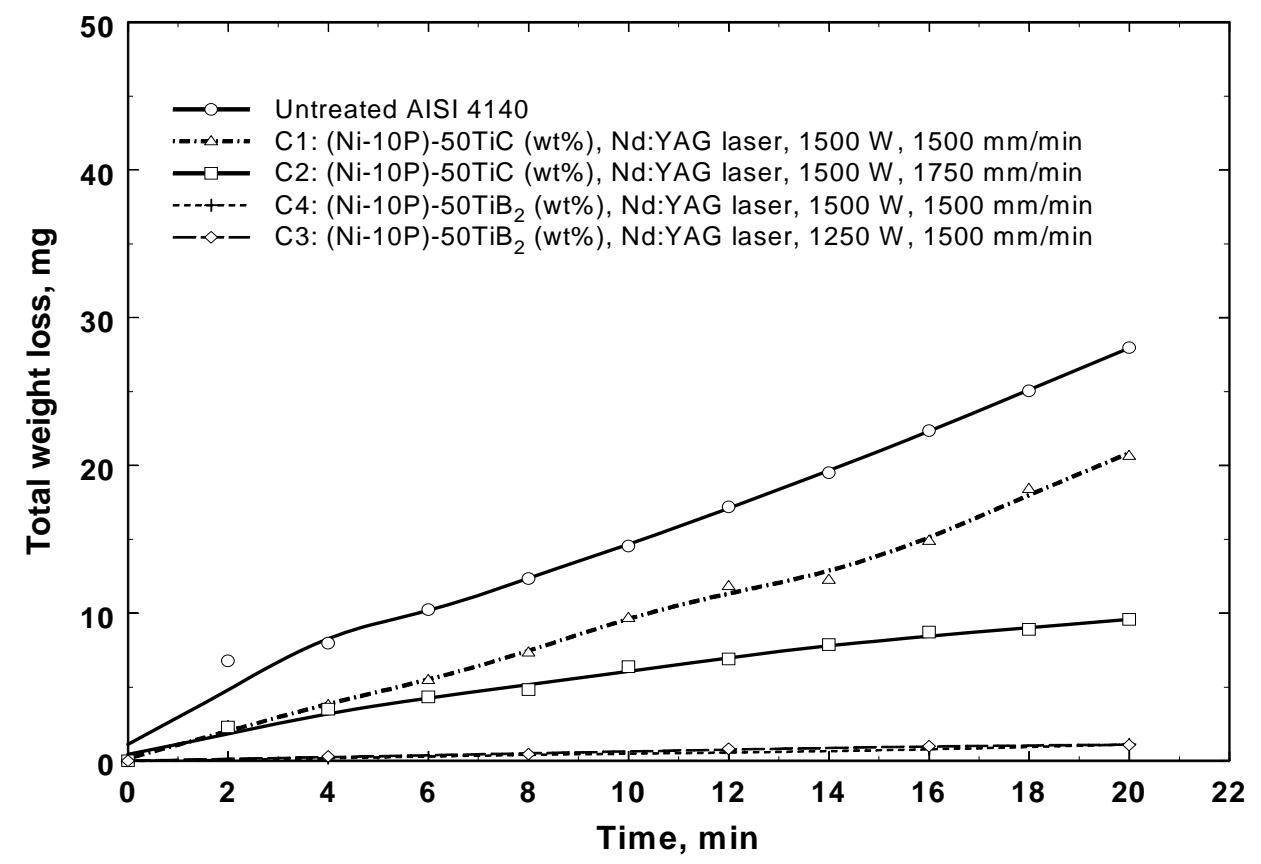

Figure 31. Block-on-ring test results of Sample C1-C4

Block-on-disk wear test was conducted to evaluate the wear resistance of the coated specimens. During the block-on-disk tests, the weight loss with respect to the wear test duration for each specimen was recorded and shown in Figures 30 and 31, respectively. The wear resistance properties of all the coated specimens were better than that of uncoated AISI 4140 steel and ASTM A36 steel. Of all coated AISI 4140 specimens, Sample C3 showed the highest wear resistance and Sample S1 exhibited the best wear resistance in the coated screen section group. The wear resistance, in terms of weight loss, of these two steels were significantly enhanced by applying Ti-based ceramic coatings. It can be seen that the wear resistance of raw coal screen panel was increased for a factor of more than one magnitude, suggesting the proposed technology has great potential applications in the surface wear resistance of coal preparation equipment. 


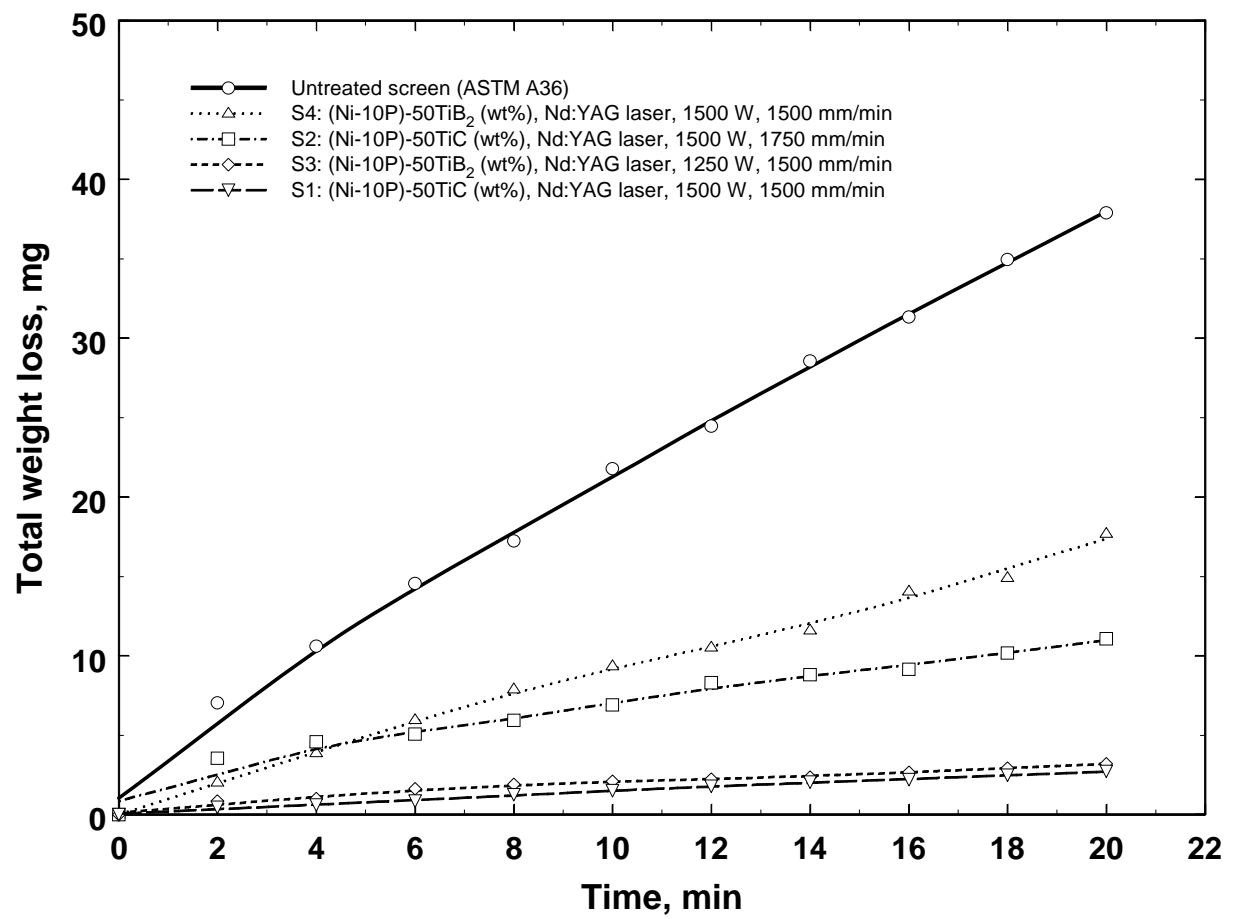

Figure 32. Block-on-ring test results of Sample S1-S4

Sliding wear, by definition, is referred to as the wear due to the relative motion in the tangential plane of contact between two solid bodies (ASTM, 2003). Raw coal screening is a continuous process in a coal preparation plant and screens are subject to wear as coal particles travel on the panels. Low wear rate and stable wear behavior are expected for a wear resistant screen. During a sliding wear process, the asperities of the weaker material may shear off first and transfer to the opposite surface (Kelly et al, 1998). It can be observed that the wear rate of the coated specimen was stable during the test, indicating breaking-off of the hard coating materials is a very smooth process, which is in agreement with the high toughness of the coating.

It should also be mentioned that during the raw coal screening process in a coal preparation plant, coal particles are fed onto the screen panels tangentially at a given speed (e.g., 10-20 cm/s in Big Creek Processing Plant). These particles then either pass through or remain on the screen decks, resulting in wear of the panel surface. In the meantime, the screen deck itself vibrates vertically to improve the probability for undersize coal particles to pass through the screen and report to the undersize product stream. Coal particles bounce up and down on the panel surface as they travel to the discharge end, which leads to impact wear when particles hit the screen panel. Therefore, screen wear in the real world consists of both sliding and impact wear. However, the vibrating amplitude of a raw coal screen is usually within 3-5 millimeters, thus sliding wear still dominates during screening process which means the wear test method employed in this research is a suitable way to simulate the wear conditions. Additionally, the ring rotating speed in this test, about $880 \mathrm{~cm} / \mathrm{s}$, was considerably higher than the 
travel speed of coal particles on the screen surface. A normal load of $4.54 \mathrm{~kg}$ was applied on the test screen section with a small contact area of $1.6 \times 10^{-4} \mathrm{~m}^{2}$. This was needed to create a rapid wear rate of the specimen.

\section{On-site Testing}

The coated screen panel worked 11 weeks before it was replaced. During this period, 993,955 tons of raw coal was processed by the screen. The service life of an uncoated screen panel at the same position is usually $5-6$ weeks, depending on the amount of coal processed. Thus, the wear life of the screen panel was doubled by applying the LSE-processed surface coating.

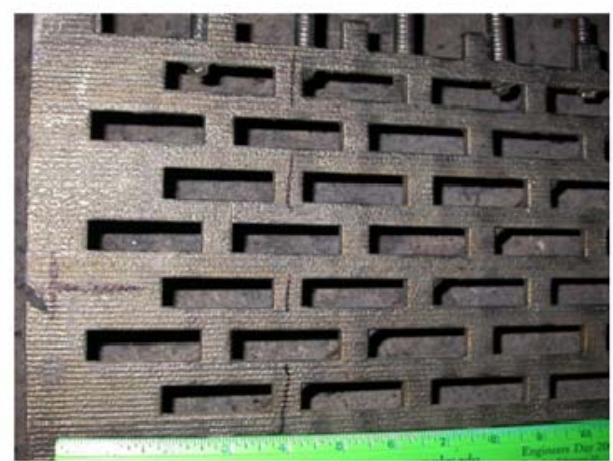

Before test

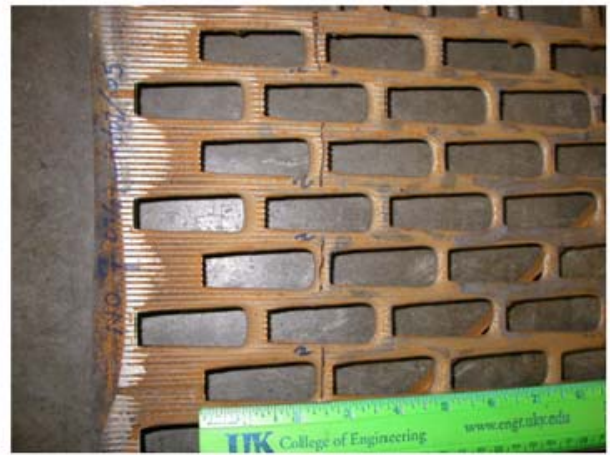

Replaced panel

Figure 33. Coated screen for on-site testing

Figure 33 demonstrates that, after 11 weeks of service, some laser tracks still can be seen on the screen, suggesting the high toughness of the coating. However, some slots of the test panel were enlarged due to wear, as shown in Figure 33. Generally, sliding wear is believed to be a dominant wear type for the screen wear. The steel bars between every two adjacent slots are the most vulnerable part in the panel, i.e., coal particles attack the bars when they are flowing down the screen surface, which makes the slot shape changed from square to trapezoid with time going on, indicating that impact wear may also play an important role determining the wear life of a screen panel. 


\section{CONCLUSIONS}

LSE coating technology was successfully applied in surface enhancement of mineral processing components. Two substrate materials which are AISI 4140 steel and ASTM A36 screen sections were coated with Ti-based ceramic materials using LSE. A range of characterization studies were performed to evaluate the coated specimens, including optical microscopy, scanning electron microscopy and XRD for the microstructural examination, microhardness testing for hardness characterization, and finally the block-on-disk wear tests to measure the wear performance of the LSE-treated components. In-plant evaluation was conducted to assess the wear performance of a coated raw coal screen panel.

Based on the results obtained in the present investigation, he following conclusions can be drawn:

1. LSE technique has been established as an effective means of producing wear resistant surfaces to meet the application requirements.

2. Surface coatings with refined microstructural features were obtained by the LSE coating process. Metallurgical bonds were formed between the coating and the substrate with the LSE process, which, in turn, increased the coating adhesion to the substrates.

3. EDS analysis provides the element distribution in the coatings. Higher amount of Ti was found near the coating surface whilst increased Fe was detected along the coating depth due to the convention effect of the LSE process.

4. XRD analysis revealed the formation of new phases in the coating layer during the LSE process. This is the characteristic feature of non-equilibrium synthesis by LSE process.

5. Of the four coated AISI 4140 specimens, Sample C3 ((Ni-10P)-50TiB 2 , $1250 \mathrm{~W}, 1500 \mathrm{~mm} / \mathrm{min}$ ) produced the highest wear resistance which is around 26 times higher that of the untreated AISI 4140 steel.

6. Sample S1 ((Ni-10P)-50TiC, $1500 \mathrm{~W}, 1500 \mathrm{~mm} / \mathrm{min})$ and $\mathrm{S} 3((\mathrm{Ni}-10 \mathrm{P})-$ $50 \mathrm{TiB}_{2}, 1250 \mathrm{~W}, 1500 \mathrm{~mm} / \mathrm{min}$ ) showed similar wear resistance enhancement during the wear test. The wear life of raw coal screen (ASTM A36 steel) increased about 10 times by applying these two coatings.

7. Initial on-site test using a coated screen panel with Metco $12 \mathrm{C}$ coating exhibited a 2-fold improvement of screen panel wear life. It should be noted that the inservice wear conditions are much more complicated than that of the laboratory wear test. In realities, a component usually fails by a mixture of wear modes, which makes it difficult to simulate in the lab testing. Laboratory wear test will be improved to better assess the wear performance of the coated component during the next year. 


\section{REFERENCES}

Agarwal, A., 1999, Laser surface engineering of composite titanium diboride coating on steel: synthesis and characterization Ph.D. dissertation, (Knoxville, TN: University of Tennessee, December 1999)

Agarwal, A. and Dahotre, N. B., 2000, "Comparative wear in titanium diboride coatings on steel using high energy density processes," Wear, v 240, n 1-2, pp 144-151

ASTM Standard, 2003, "Wear and Erosion; Metal Corrosion, Annual book of ASTM standards," Volume 03.02, p172, ASTM international, West Conshohocken, PA.

Cutler, R., 1995, "Engineering properties of borides" In Engineering Materials Handbook, Ceramic and Glasses. ASM International, Metals Park, OH, pp. 787803.

Dahotre, N.B. (1998), in: Lasers in surface engineering, ASM International, Materials Park, $\mathrm{OH}$.

Davis, J.R.(Ed), 1998, Metals Handbook, 2nd edition; ASM International, Materials Park, $\mathrm{OH}, \mathrm{USA}$.

Durman, R.W., 1988, "Progress in abrasion resistant materials for use in comminution processes," International Journal of Minereral. Processing, pp. 381-399

Foster, J., 1996, "Ceramic applications for wear protection of pipe lines and cyclones," Key Engineering Materials, 122-124, pp. 247-278.

Guo, Z. and Derby, B., 1998, "Stabilization of TiBx-coated SiC fibers by nitridation," Scripta Materials, 38(11), pp.1629-1634.

Kelly, J.; Nagarathnam, K.; Mazumder, J., 1998, "Laser cladding of cast aluminumsilicon alloys for improved dry sliding wear resistance", Journal of Laser Applications, v 10, n 2, pp. 45-54.

Khedkar, J.; Khanna, A.S. and Gupt, K.M., 1997, "Tribological behaviour of plasma and laser coated steels," Wear, v 205, n 1-2, pp 220-227

Laurila, M.J., 1998, "Trends in the U.S. coal preparation industry," Coal Age, 103(5), pp. $53-54$

Laurila, M.J. and Budge, G., 2000, "Benchmarking coal prep practice: An Update," in Proceedings of $17^{\text {th }}$ International Coal Preparation Exhibition \& Conference, Lexington, KY, USA, pp. 51-55.

Leonard, J. W. and Hardinge, B.C., 1991, Coal preparation, 5th edition, Society for Mining, Metallurgy and Exploration, Inc., Littleton, CO, p 223. 
Mazumder, J., 1996, "Laser assisted surface coatings," in Metallurgical and Ceramic Protective Coatings, ed. Kurt H. Stern, Champman and Hall, London, pp 74-111

Mining Journal Ltd., 1999, Mining Annual Review, London, United Kindom.

Norman, T.E., 1980, "Wear in ore processing machinery," in: Wear Control Handbook Peterson, M.B. and Winor, W.O. (Eds.), ASME, pp. 109-115

Nonnen, F.A., 1985, "Wear resistant materials reduce costs," Bulk Solids Handling, 5(5), pp. 1035-1039.

Raghunath, C.; Bhat, M.S.; Rohatgi, P.K. 1995, "In situ technique for synthesizing FeTiC composites," Scripta Metallurgical Material, v 32, n 4, pp. 577-582 